\title{
DNA damage activates mTORC1 signaling in podocytes leading to glomerulosclerosis
}

Fabian Braun ${ }^{1,2 *}$, Linda Blomberg ${ }^{1,9}$, Roman Akbar-Haase ${ }^{1,9}$, Victor G. Puelles ${ }^{2}$, Milagros N. Wong $^{2}$, Mahdieh Rahmatollahi ${ }^{1,9}$, Damian Fermin $^{3}$, Gisela G. Slaats ${ }^{1,9}$, Sybille Koehler ${ }^{1}$, Paul T. Brinkoetter ${ }^{1,9}$, Maja T. Lindenmeyer ${ }^{2}$, Clemens D. Cohen ${ }^{2,4}$, Martin Kann ${ }^{1,9}$, Wilhelm Bloch ${ }^{5}$, Matthew G. Sampson ${ }^{6,7,8}$, Tobias B. Huber ${ }^{2}$, Bernhard Schermer ${ }^{1,9,10}$, Thomas Benzing ${ }^{1,9,10}$, Björn Schumacher ${ }^{9,10,11}$, and Christine E. Kurschat ${ }^{1,9 *}$

1Department II of Internal Medicine and Center for Molecular Medicine Cologne, University of Cologne, Faculty of Medicine and University Hospital Cologne, Cologne, Germany

2III. Department of Medicine, University Medical Center Hamburg-Eppendorf, Hamburg, Germany

3Department of Pediatrics-Nephrology, University of Michigan, Ann Arbor, Michigan

${ }^{4}$ Nephrological Center, Medical Clinic and Polyclinic IV, University of Munich, Munich, Germany

${ }^{5}$ Department of Molecular and Cellular Sport Medicine, German Sport University Cologne, Cologne, Germany

${ }^{6}$ Division of Nephrology, Boston Children's Hospital, Boston, Massachusetts, USA

${ }^{7}$ Harvard Medical School, Boston Massachusetts, USA

${ }^{8}$ Broad Institute, Cambridge, Massachusetts, USA

${ }^{9}$ Cologne Excellence Cluster on Cellular Stress Responses in Aging-Associated Diseases, University of Cologne, Germany

${ }^{10}$ Systems Biology of Ageing Cologne, SyBaCol, University of Cologne, Germany

${ }^{11}$ Institute for Genome Stability in Aging and Disease, Medical Faculty, University of Cologne, Germany

${ }^{*}$ Correspondence should be addressed to:

\author{
Christine E. Kurschat \\ Nephrology Research Lab \\ CECAD \\ University of Cologne \\ Joseph Stelzmann-Straße 26 \\ 50931 Cologne, Germany \\ Tel +49-221-4784480 \\ Fax +49-221-478 5959 \\ E-mail: christine.kurschat@uk-koeln.de \\ Fabian Braun \\ E-mail: fa.braun@uke.de \\ Twitter:@fab braun
}




\section{Abstract:}

DNA repair is essential for preserving genome integrity and ensures cellular functionality and survival. Podocytes have a very limited regenerative capacity, and their survival is essential to maintain kidney function. While podocyte depletion is a hallmark of glomerular diseases, the mechanisms leading to severe podocyte injury and loss remain largely unclear. We detected perturbations in DNA repair in biopsies from patients with various podocyte-related glomerular diseases and identified single-nucleotide polymorphisms associated with the expression of DNA repair genes in patients suffering from proteinuric kidney disease. Genome maintenance through nucleotide excision repair (NER) proved to be indispensable for podocyte homeostasis. Podocyte-specific knockout of the NER endonuclease co-factor Ercc1 resulted in accumulation of DNA damage, proteinuria, podocyte loss and glomerulosclerosis. The response to this genomic stress was fundamentally different to other cell types, as podocytes activate mTORC1 signaling upon DNA damage in vitro and in vivo. 


\section{Introduction:}

Most cells of the body are constantly subjected to various endogenous and exogenous DNA damaging agents (Lindahl and Nyberg, 1972; Loeb and Harris, 2008). Therefore, cells depend on numerous DNA repair mechanisms to counteract this genomic stress (Chatterjee and Walker, 2017). Mutations in DNA repair genes result in a variety of pathologies ranging from cancer to progeroid syndromes (Ghosal and Chen, 2013; Wolters and Schumacher, 2013). The specific importance of genome maintenance in cells with limited regenerative capacity is demonstrated by the prevalence of neurodegeneration as a hallmark of DNA repair deficiency syndromes (Madabhushi et al., 2014).

Similar to neurons, the glomerular epithelial cells, podocytes, are terminally differentiated cells that are not replaced post-development (Wanner et al., 2014). Podocytes are an integral part of the primary filtration unit of the kidney (Butt et al., 2020) and their loss is a leading causes of chronic kidney disease, such as diabetes, hypertension and glomerulopathies, with ensuing loss of protein into the urine (Chen et al., 2019). The precise pathomechanisms leading to podocyte depletion are incompletely understood, and treatments to better protect this finite number of cells are lacking (Rosenberg and Kopp, 2017).

Lately, the first studies have indicated the importance of genome maintenance for renal health (Hakroush et al., 2014; Marshall et al., 2006). Mutations in the kinase, endopeptidase and other proteins of small size (KEOPS) complex genes caused proteinuria and induced DNA damage response (DDR) in vitro (Braun et al., 2017). Likewise, glomerular DNA damage was found to be associated with declining kidney function (Hayashi et al., 2020) and cells isolated from the urine of patients suffering from diabetes and hypertension showed increased levels of DNA strand breaks (Hishikawa et al., 2020). First evidence of nucleotide excision repair (NER) as an essential pathway in kidney health was recently provided through the identification of Ercc1 mutations causing kidney dysfunction (Apelt et al., 2020). However, a link between DNA damage and podocyte loss, to date, remains unclear.

Several studies have proposed an interplay between DNA damage signaling and the mechanistic target of rapamycin (mTOR) pathway with factors induced by DNA damage exhibiting repressive effects on mTOR-complex1 (mTORC1) (Budanov and Karin, 2008; Reiling and Hafen, 2004; Wu et al., 2018) and increased mTORC1 activity leading to genomic stress (Chebel et al., 2016; Dominick et al., 2016; Xie et al., 2018). This is of particular interest for podocytes, as they are highly dependent on a rigorous control of mTOR activity. While mTORC1-driven hypertrophy is a protective response upon podocyte depletion (Nishizono et al., 2017; Puelles et al., 2019; Zschiedrich et al., 2017), mTORC1 overactivation drives pathologic hyperproliferation and sclerosis (Inoki et al., 2011; Kurayama et al., 2011). In line with these findings, side effects of pharmacological mTOR inhibition entail proteinuria and 
glomerular scarring (Butani, 2004; Cho et al., 2007; Dittrich et al., 2004; Hochegger et al., 2008; Izzedine et al., 2005; Letavernier et al., 2007; Sennesael et al., 2005).

In this study, we identified perturbations in the expression of NER genes in glomeruli from various human glomerular diseases associated with podocyte loss. Podocyte-specific NER impairment resulted in DNA damage accumulation, podocyte loss, and glomerulosclerosis in mice. Strikingly, both in vivo and in vitro analyses delineated mTORC1 activation upon DNA damage, indicating a cell-type specific response. Furthermore, we report single nucleotide polymorphisms (SNPs) near DNA repair genes associated with their expression in proteinuric patients. These results directly link genome maintenance with mTORC1 signaling and glomerular diseases.

\section{Results:}

We screened the European renal cDNA biobank $(E R C B)$ for the expression of hallmark DNA repair and nucleotide excision repair genes in micro-dissected human glomeruli from biopsies of patients with various glomerular diseases compared to controls (Fig. S1A ; Tbl. S1). This screen revealed the most pronounced differences between kidney disease characterized by podocyte injury without loss (minimal change disease, MCD), and kidney disease associated with extensive podocyte damage and loss (focal segmental glomerulosclerosis, FSGS) (Fig.1A). This was even more apparent comparing genes involved in NER, indicating an involvement of NER in the pathogenesis of podocyte damage (Fig. 1A, S1B).

A well-established model of NER disruption is the deletion of DNA excision repair protein Ercc1, the cofactor of the endonuclease Ercc4 (XPF), both found to be differentially expressed in the ERCB analysis (Doig et al., 2006; Karakasilioti et al., 2013; Niedernhofer et al., 2006). We generated a constitutive podocyte-specific knockout of Ercc1 using the cre-loxP system in mice of a mixed ICR-FVB background (Moeller et al., 2003) (Fig. 1B \& S1C). Mice carrying the podocyte-specific knockout (pko) had a decreased lifespan of 10-15 weeks while cre negative animals (ctrl) and cre positive animals heterozygous for the floxed Ercc1 allele (het) were investigated for up to 72 weeks without overt abnormalities (Fig. S1E, F \& G). Weight gain after birth was normal up to week 9, with a pronounced decrease afterwards (Fig. 1C). This weight drop was accompanied by significant albuminuria as well as elevated serum creatinine and urea levels, starting at week 11 (Fig. 1D-F).

At that timepoint, Ercc1pko mice had developed severe generalized renal damage, including glomerulosclerosis, interstitial fibrosis and tubular atrophy with protein casts at week 13 (Fig. $1 G)$. Since DNA damage repair may play a role during organ development, we established an inducible podocyte-specific knockout of Ercc1 using a tamoxifen-sensitive podocyte-specific cre recombinase (Fig. $1 \mathrm{H})$. Deletion of Ercc1 in podocytes of mice 8 weeks after birth resulted 
in a similar phenotype, including proteinuria, glomerulosclerosis, and a shortened lifespan (Fig. $1 \mathrm{I}, \mathrm{J} \& \mathrm{~S} 1 \mathrm{H})$.

Ultrastructural alterations were detected in 9 week-old Ercc1pko glomeruli in the form of focally effaced foot processes not present in 7 week-old animals (Fig. 2A). Further indication of podocyte stress was given by perturbations and eventually loss of the slit diaphragm protein nephrin between weeks 9 to 13 (Fig. 2B). We did not detect significant differences in podocyte number, glomerular hypertrophy or a decrease in podocyte density at week 9 (Fig. 2C \& S2A). In contrast, glomeruli from week 11 Ercc1pko mice showed a wide range of abnormalities with varying degrees of down-regulation of podocyte-specific proteins (Fig. 2D), indicative of severe podocyte injury and loss.

Foci of phosphorylated histone 2A.X ( $\mathrm{YH} 2 \mathrm{~A} . \mathrm{X})$, a bona fide marker for DNA damage, were significantly increased in both number and area in podocyte nuclei of Ercc1pko glomeruli at week 9 (Fig. 2E \& S2B-D). Given the observation of rapidly progressing glomerulosclerosis and renal failure after this timepoint we determined 6 or more $\mathrm{YH} 2 \mathrm{~A} . \mathrm{X}$ foci to define Ercc1pko podocytes prone to cellular damage and loss. At 9 weeks of age, 16,4\% of Ercc1pko podocytes were categorized into this at-risk group. Strikingly, we also observed a smaller number of $\mathrm{YH} 2 \mathrm{~A} . \mathrm{X}$ foci in almost all wildtype podocyte nuclei indicative of constant DNA damage occurrence and repair in healthy glomeruli. At later timepoints, single podocytes with a $\mathrm{YH} 2 \mathrm{~A} . \mathrm{X}$ signal covering larger areas of the nuclei became apparent in Ercc1pko glomeruli (Fig. 2F).

To further investigate the molecular changes occurring in podocytes upon genomic stress, we induced DNA damage through mitomycin C treatment and UV irradiation in vitro (Fig. 3A), which led to significant increases of $\mathrm{YH} 2 \mathrm{~A} . \mathrm{X}$ (Fig. 3B) and accumulation of the DNA damage response protein p53 in the nucleus (Fig. 3C). DNA damage induced an increase in phosphorylation of mTORC1 downstream target ribosomal protein S6 (S6Rp) in podocytes (Fig. 3D). This phosphorylation was completely abrogated by mTORC1 inhibitor rapamycin and reduced by serum starvation, a well-known mTORC1 modulator (Settembre et al., 2013). Next, we investigated mTORC1 activation in our podocyte-specific mouse model of impaired NER and observed a significant increase in pS6Rp-positive cells in pko glomeruli at 9 weeks of age (Fig. 3E). Further analysis revealed that more than $40 \%$ of podocytes showed mTORC1 activation (Fig. 3E). We detected similar results when investigating S6Rp phosphorylation in patient biopsies with proven FSGS. In comparison with glomeruli of MCD patients, FSGS glomeruli comprised significantly more pS6Rp-positive cells (Fig. 3F). This finding was accompanied by a significant increase in podocyte-specific nuclear $\mathrm{YH} 2 \mathrm{~A}$.X foci in FSGS glomeruli, mirroring our findings in 9 week-old Ercc1pko mice (Fig. 3G \& S3).

Ancillary, similar differences in both podocyte-specific S6Rp phosphorylation and YH2A.X foci were noted when comparing young and aged glomeruli of wild type mice (Fig.S4 A-C) and 
human nephrectomy samples of different ages (Fig.S4 E-H). These results suggest an association between DNA damage and aging in podocytes, possibly explaining age-related podocyte loss (Puelles et al., 2019).

The striking phenotype observed in Ercc1pko mice and the accumulation of DNA damage in human podocytes during the development of glomerulopathies lead us to assess whether genetic variants associated with glomerular mRNA expression of DNA repair genes could be detected in patients with sclerotic glomerular diseases. The data base NephQTL contains the expression quantitative trait loci of 187 patients suffering from proteinuric kidney diseases. We performed a subgroup analysis of those patients diagnosed with FSGS (Table S2) and were able to identify SNPs associated with alterations in the expression of DNA repair genes (Table $1 \&$ S3). These sites in the genome represent interesting targets for further fine-mapping and mechanistic investigation, with the hope of eventual illumination of a targeted therapeutic strategies to alter the glomerular DNA damage response.

\section{Discussion:}

The presented study allows two principal conclusions. First, DNA repair mechanisms are affected in glomerular disease. These mechanisms are indispensable for podocyte homeostasis and single nucleotide polymorphisms (SNPs) associated with glomerular mRNA levels of DNA repair genes can be identified in patients suffering from proteinuric kidney disease. Second, podocytes do not react to DNA damage by a repression of the mTORC1 pathway, but by a striking upregulation before the onset of podocyte loss. This is the first report drawing a connection between DNA repair mechanisms and glomerular diseases via mTORC1 signaling.

Only recently has the importance of DNA repair sparked larger interest in the field of podocyte biology. Due to their often deleterious clinical phenotypes the description of glomerular abnormalities in syndromes caused by mutations in DNA repair genes is scarce (Chehida et al., 2017; Hirooka et al., 1988). However, there is evidence for a podocyte involvement underlined by reports of proteinuria and nephrotic syndrome (Doig et al., 2006; Faridounnia et al., 2015; Kondo et al., 2016). The same holds true for factors involved in other forms of DNA maintenance such as the KEOPS complex (Braun et al., 2017; Hecker et al., 2009) or KAT5, a contributor to DNA methylation and non-homologous endjoining repair (Hishikawa et al., 2019). The Itoh group further linked the proteinuric phenotype to DNA double strand breaks and methylation in the promotor region of slit diaphragm protein nephrin and established an association of DNA double strand breaks in glomeruli of patients suffering from $\lg A$ nephropathy (Hayashi et al., 2020; Hishikawa et al., 2020). Our analysis adds considerably to this body of evidence, as we identify multiple factors of DNA maintenance, in particular of NER, 
to be transcriptionally altered in glomeruli of various renal diseases involving pronounced podocyte damage and loss. The precise evaluation of perturbations in every single one of the identified genes goes beyond the scope of this manuscript, but we investigated the importance of NER and the subsequent podocyte-specific reaction to accumulating DNA damage to an unreported depth in vivo.

To what extent glomerular epithelial cells are subjected to genomic stress remains unclear. For the first time, this study reveals the occurrence of DNA damage in podocytes under healthy conditions indicating a need for constant DNA maintenance and repair. This finding is in line with studies investigating glomerular expression profiles of a partial Ercc1 ko (Schermer et al., 2013) and an adipose-tissue specific Ercc1 ko that described a low amount of $\mathrm{YH} 2 \mathrm{~A} . \mathrm{X}$ foci occurring in adipocytes of control animals as well (Karakasilioti et al., 2013). A major factor contributing to this stress, most likely, results from damaging agents in the patients' sera, as these are constantly filtered into the primary urine in which the podocytes are emerged in. Deficiency in the repair of the latter seems to be compensable up to a certain threshold as podocyte loss, proteinuria and glomerular sclerosis only became apparent after week 9 . We identified the accumulation of 6 or more $\mathrm{YH} 2 \mathrm{~A}$.X foci to render podocytes deficient of Ercc1 prone to further damage and possible detachment in our mouse model.

The interplay of DNA damage, its repair and the mTOR pathway have been a subject of numerous studies, specifically in the field of cancer biology. The drosophila homologs for DNA damage-inducible transcript 4 protein (DDIT4/RTP801/REDD1) were found to inhibit mTORC1 signaling upstream of Tuberous sclerosis 1 and 2 (TSC1/2) (Reiling and Hafen, 2004). Similarly, tumor suppressors p53 and PEST containing nuclear protein (PCNP) repress mTOR through the expression of Sestrin 1 and 2 (Budanov and Karin, 2008) or the dephosphorylation of RAC-alpha serine/threonine-protein kinase (AKT), respectively (Wu et al., 2018). Strikingly, we observed that podocytes both in vitro and in vivo reacted to endogenous accumulation or exogenous infliction of DNA damage with an upregulation of the mTORC1 pathway. Herein lies a fundamental difference to other cells and a potential disease mechanism as numerous studies have depicted the importance of a tight regulation of $\mathrm{mTORC} 1$ for podocyte health and the deleterious effect of both overactivation and repression in diseases (Gödel et al., 2011; Inoki et al., 2011; Ising et al., 2015; Liebau et al., 2013; Puelles et al., 2019; Zschiedrich et al., 2017). Since mTORC1 activation occurs in Ercc1pko podocytes at 9 weeks, a timepoint of no overt podocyte loss, only mild ultrastructural differences, and significant accumulation of DNA damage foci, our data indicate a direct link between genomic stress and mTORC1 activation in podocytes.

A growing body of evidence suggests that mTORC1 activity reduces the capacity of successful DNA repair (Chebel et al., 2016; Dominick et al., 2016), e.g. through ribosomal S6 kinase 
(S6K)-dependent phosphorylation of E3 ubiquitin-protein ligase RNF168 (Xie et al., 2018). However, upon podocyte depletion, remaining podocytes on the glomerular tuft, counteract the loss of neighbouring cells through mTORC1-mediated hypertrophy (Puelles et al., 2019) which impairs proper DNA repair. We, therefore, hypothesize that this reaction can lead to a downward spiral of insufficient DNA maintenance and mTORC1 activation triggering excessive podocyte loss.

We used a cohort of FSGS patients with kidney expression data to perform a targeted cis eQTL study and identified common SNPs associated with altered expression of DNA repair genes. This is of particular interest since there seems to be a broad interplay between the gene products exerting functions beyond their canonical pathways in genome maintenance (Mulderrig and Garaycoechea, 2020). Such sites in the genome, therefore, warrant further investigation on whether they can be exploited for therapeutic strategies with the goal of altering glomerular DNA damage repair. For instance, decreased expression of DNA repair genes could render podocytes prone to increased accumulation of DNA damage upon mTORC1 activation thereby rendering a subgroup of patients prone to the development of glomerular scarring.

The importance of Ercc1 in maintaining podocyte homeostasis is consistent with the role of NER in postmitotic cell types that is particularly apparent in the neurodegenerative pathologies that are typical for NER deficiency syndromes(Wolters and Schumacher, 2013). The role of NER in repairing transcription-blocking lesions might thus play a pivotal role in podocytes that need to maintain the integrity of transcribed genes during the entire lifespan or the organism. Even in hepatocytes, Ercc1 -/delta mice showed a considerable block of transcription indicative of transcription-coupled mechanisms being stalled (Milanese et al., 2019),47.

In conclusion, we have identified nucleotide excision repair as an essential mechanism of DNA maintenance in podocyte homeostasis. The presented study characterizes the activation of mTORC1 signaling as a specific response of podocytes to DNA damage and accumulation of the latter as one novel hallmark of podocyte loss and glomerular disease. 


\section{Methods:}

\section{$E R C B$}

Human microarray analysis 167 genes involved in DNA repair and nucleotide excision repair were compiled from the hallmark gene set "DNA-Repair" from the Molecular Signatures Database (MSigDB) Collection (Liberzon et al The Molecular Signatures Database (MSigDB) hallmark gene set collection. Cell Syst. 2015 Dec 23;1(6):417-425) and upon literature research. Human kidney biopsies and Affymetrix microarray expression data were obtained within the framework of the European Renal cDNA Bank - Kröner-Fresenius Biopsy Bank (C. D. Cohen, et al Kidney international 61, 133-140 (2002)). Diagnostic biopsies were obtained from patients after informed consent and with approval of the local ethics committees. Following renal biopsy, the tissue was transferred to RNase inhibitor and micro-dissected into glomeruli and tubulo-interstitium. Total RNA was isolated, reverse transcribed and amplified to a protocol previously reported (Cohen et al PNAS 103: 5682-5687 (2006)). Fragmentation, hybridization, staining and imaging were performed according to the Affymetrix Expression Analysis Technical Manual (Affymetrix, Santa Clara, CA, USA). Published datasets of glomerular samples were analysed for mRNA expression levels. Analysis included datasets from patients with minimal change disease (MCD; $n=14)$, focal segmental glomerulosclerosis (FSGS; $n=23$ ), membranous nephropathy (MGN; $n=21$ ), IgA nephropathy (Glom:n=27), , and hypertensive nephropathy ( $\mathrm{HTN} ; \mathrm{n}=15)$ as well as controls (living donors (LD); $n=42$ ) (GSE99340, LD data from: GSE32591, GSE37463). CEL file normalization was performed with the Robust Multichip Average method using RMAExpress (Version 1.0.5) and the human

Entrez-Gene custom CDF annotation from Brain Array version 18 (http://brainarray.mbni.med.umich.edu/Brainarray/default.asp). To identify differentially expressed genes, the SAM (Significance Analysis of Microarrays) method (V. G. Tusher, et al. PNAS 98, 5116-5121 (2001)) was applied using SAM function in Multiple Experiment Viewer (TiGR MeV, Version 4.9). A q-value below $5 \%$ was considered to be statistically significant. The resulting gene expression list was censored for genes, whose products were detected in a transciptomic and proteomic analysis of wild-type murine podocytes (Rinschen et al., 2018). Mice

Mice were bred in a mixed FVB/CD1 (Ercc1pko) or FVB/CD1/C57BL6 (Ercc1ipko) background. All offspring was born in normal mendelian ratios with FACS-sorted podocytes of animals carrying the podocyte-specific knockout (pko) depicting a profound decrease in Ercc1 gene expression levels (Fig. S1D). Mice were housed in the animal facility of the Center for Molecular Medicine Cologne or the Cluster of Excellence - Cellular Stress Responses in Aging-Associated Diseases. Following federal regulations, the Animal Care Committee of the University of Cologne reviewed and approved the experimental protocols. Animals were 
housed at specific pathogen-free (SPF) conditions with three-monthly monitoring according to FELASA suggestions. Housing was done in groups of less than six adult animals receiving CRM pelleted breeder and maintenance diet irradiated with 25 kGy (Special Diet Services, Witham, UK), and water ad libitum. Spot urine was collected once a week during cage changes or during sacrifice.

Mice were anaesthetized by intraperitoneal injection of $10 \mu \mathrm{l}$ per g bodyweight of $0,01 \%$ xylocaine and $12,5 \mathrm{mg} / \mathrm{ml}$ ketamine - blood was drawn from the left ventricle into a syringe rinsed with Heparin sulfate, and animals were perfused with cold phosphate buffered saline (PBS). Kidneys were excised and embedded in OCT (Sakura, Torrance, CA) and frozen at $80^{\circ} \mathrm{C}$ or fixed in $4 \%$ neutral buffered formalin and subsequently embedded in paraffin.

\section{Podocyte isolation}

To isolate primary podocytes, Ercc1flox/flox mice heterozygous for the R26mTmG and NPHS2.Cre transgene were sacrificed and kidneys were used for glomerular preparation, as previously described (Rinschen et al., 2018). The glomeruli were digested, and the single-cell suspension was used for fluorescence-activated cell sorting.

qPCR Analysis

Total ribonucleic acid (RNA) was extracted from podocytes of Ercc1/Pod:Cre/mTmG mice using Direct-zol ${ }^{\mathrm{TM}}$ RNA MiniPrep Kit (cat. no. R2052, Zymo Research). Isolation of glomeruli, preparation of a glomerular single-cell suspension and fluorescence-activated cell sorting was done as previously described (Wanner et al., 2014). Podocytes were sorted into TriReagent (cat. no. 93289, Sigma-Aldrich). The complementary deoxyribonucleic acid (cDNA) was synthesized with High Capacity cDNA Reverse Transcription Kit (cat. no. 4368814, Applied Biosystems). PCR was performed using TaqMan ${ }^{\mathrm{TM}}$ Gene Expression Master Mix (cat. no. 4369016, Applied Biosystems) and the Applied Biosystems Real-time PCR system. Real-time PCR was measured with three reactions in each gene target (triple replication technique). The sequence of the PCR primer used for Ercc1 was: 5'- AGCCAGACCCTGAAAACAG-3' and 5'CACCTCACCGAATTCCCA-3' in PrimeTime Mini qPCR Assay for Ercc1 (Assay-ID:. Mm.PT.58.42152282, IDT). The gene expression was calculated using comparative cycle threshold method and normalized to RNA polymerase II subunit A (Polr2a). The relative fold change of Ercc1 expression in knockout mice was compared with WT and heterozygous mice. Urinary Albumin ELISA \& Creatinine measurement

Urinary albumin levels were measured with a mouse albumin ELISA kit (mouse albumin ELISA kit; Bethyl Labs, Montgomery, TX, USA ). Urinary creatinine kit (Cayman Chemical, Ann Arbor, MI, USA ) was used to determine corresponding urinary creatinine values. For Coomassie Blue detection of albuminuria, spot urine of mice was diluted 1:20 in 1x Laemmli Buffer and 
urinary proteins separated using Poly-Acrylamide Gel Electrophoresis with subsequent Coomassie gel stain.

\section{Plasma Creatinine and Urea measurement}

Blood samples were centrifuged at $400 \mathrm{~g} 4^{\circ} \mathrm{C}$ for 20 minutes and plasma samples subsequently stored at $-20^{\circ} \mathrm{C}$ until further analysis. Creatinine and Urea were measured using standard clinical protocols by the Department of Clinical Chemistry of the University of Cologne.

\section{Histologic analysis}

To assess morphological changes in light microscopy we performed periodic acid Schiff staining. For specific antibody stainings sections were deparaffinized in Xylene (VWR, Darmstadt, Germany), rehydrated in decreasing concentrations of ethanol and subjected to heat-induced antigen retrieval in 10mM Citrate Buffer $\mathrm{pH} 6$ for 15 minutes. Peroxidase blocking was performed in methanol mixed with $3 \%$ hydrogen peroxidase (Roth, Karlsruhe, Germany) followed by Avidin/Biotin Blocking (Vector, Burlingame, CA, USA) for 15 minutes each. After incubation in primary antibody (anti-phospho-S6 Ribosomal Protein (Ser235/236) \# 4858 Cell Signaling Technology) 1:200 in TBS 1\% BSA at $4^{\circ} \mathrm{C}$ overnight, sections were washed in TBS and incubated in biotinylated secondary antibody (Jackson Immunoresearch, West Grove, USA) 1h at room temperature. For signal amplification the ABC Kit (Vector, Burlingame, CA, USA) was used before applying 3,30-diaminobenzamidine (Sigma-Aldrich, St Louis, USA) as a chromogen. Hematoxylin was used for counterstaining. After dehydration slides were covered in Histomount (National Diagnostics, Atlanta, USA).

\section{Immunofluorescence Staining}

Parrafin embedded tissue was cut in to $3 \mu \mathrm{m}$ sections and processed according to published protocols (Puelles et al., 2015). Primary antibodies (anti-yH2A.X \#2577s - Cell Signalling Technology, anti-nephrin \#GP-N2 - Progen, anti-synaptopodin \#65294 - Progen, anti-Dach1 \#HPA012672 - Sigma Aldrich (Endlich et al., 2018), anti-phospho-S6 Ribosomal Protein (Ser235/236) \# 4858 - Cell Signaling Technology) were used at 1:200 dilution. Far-red fluorescent DNA dye Draq 5 was used as a nuclear marker.

Cells were processed according to published protocols (Liebau et al., 2013). Primary antibody (anti-p53 \#p53-protein-cm5 Leica Biosystems) was used at 1:200 dilution.

For $\mathrm{YH} 2 \mathrm{~A} . \mathrm{X}$ foci quantification, a custom FIJI macro was used. In brief, podocyte nuclei were identified through surrounding synaptopodin staining, segmented using the freehand tool and split into single channels. Draq 5 channel was converted into binary image using auto threshhold "otsu dark" with subsequent particle measurement (range 5-Infinite) to determine nuclear area. YH2A.X channel was converted into binary image using auto threshhold "MaxEntropy dark" with subsequent particle measurement (range 0.02-Infinite) to determine foci number and area. 


\section{Electron Microscopy}

Mice were perfused with $4 \%$ paraformaldehyde and $2 \%$ glutaraldehyde in $0.1 \mathrm{M}$ sodium cacodylate, $\mathrm{pH}$ 7.4. Postfixation was performed in the same buffer for 2 additional weeks at $4^{\circ} \mathrm{C}$. Tissue was osmicated with $1 \% \mathrm{OsO} 4$ in $0.1 \mathrm{M}$ cacodylate and dehydrated in increasing ethanol concentrations. Epon infiltration and flat embedding were performed following standard procedures. Toluidine blue was used to stain semithin sections of $0.5 \mu \mathrm{m}$ ). Thirtynanometer-thick sections were cut with an Ultracut UCT ultramicrotome (Reichert) and stained with $1 \%$ aqueous uranylic acetate and lead citrate. Samples were studied with a Zeiss EM 902 electron microscope (Zeiss, Oberkochen, Germany) and Zeiss EM 109 electron microscope (Zeiss).

\section{In vitro Experiments}

Conditional immortalized murine podocytes were a gift by Stuart Shankland. Cells were cultured as previously described (Shankland et al., 2007). Briefly, immortalized podocytes were cultured in RPMI media supplemented with 10\% FBS and IFNY (Sigma-Aldrich, Taufkirchen, Germany). Cells proliferated at $33^{\circ} \mathrm{C}$ until they reached a confluence of $60-70 \%$. Differentiation of podocytes was induced by seeding the cells at $37^{\circ} \mathrm{C}$ on Primaria plastic plates (BD Biosciences, San Jose, CA, USA) in the absence of IFNc. After 10 days of differentiation cells were treated with 5 or, respectively, $10 \mu \mathrm{g} / \mathrm{ml}$ mitomycin C (\#M0503 - Sigma-Aldrich, Taufkirchen, Germany) for $2 \mathrm{~h}$. Afterwards cells were washed once with Phosphate-Buffered Saline and cultured in normal mitomycin C-free medium for additional 6 hours before further processing. The absence of mycoplasm infection was tested regularly using the mycoplasm detection kit from Minerva biolabs (Minerva Biolabs, Berlin, Germany).

\section{Western Blot analysis}

SDS-PAGE was used for protein size separation with subsequent blotting onto polyvinylidene difluoride membranes and visualized with enhanced chemiluminescence after incubation of the blots with corresponding antibodies (Phospho-Histone H2A.X (Ser139); Phospho-S6 Ribosomal Protein (Ser235/236) (D57.2.2E); S6 Ribosomal Protein (5G10) - Cell Signaling Technology; alpha Actin - Developmental Studies Hybridoma Bank; beta-Tubulin (E7) Developmental Studies Hybridoma Bank)

eQTL Analysis

For the subgroup analysis of FSGS cohort the procecdure described in Gillies et al., 2018. was used with the following exceptions: only FSGS patients were used in this analysis $(\mathrm{N}=87)$ and only RNAseq expression data for glomerular samples were utilized. Briefly cis-eQTLs were identified using MatrixEQTL from among variants that were located either within the annotated boundaries of a gene or it's surrounding region (+/- 500kb) (Shabalin et al., 2012). We then adjusted for age, sex, principle components of genetic ancestry and the first 5 PEER factors 
(Stegle et al. 2010). The genetic ancestry was calculated using LD-pruned WGS data from across all 87 patients using the EPACTS tool (https://genome.sph.umich.edu/wiki/EPACTS). The gene-level FDR for the MatrixEQTL was controlled using TORUS (Wen, 2016). Fine mapping of the eQLTs was performed using the DAP algorithm (Wen, et al, 2016).

\section{Statistics}

If not stated otherwise unpaired two tailed Student's t test was used to compare two groups, and $p$ values $\leq 0.05$ were considered significant. For multiple group comparisons, we applied 1-way ANOVA followed by Tukey's post hoc correction. Statistics were performed using GraphPad Prism 8.

\section{Study approval}

All investigations involving human specimen have been conducted according to the Declaration of Helsinki following approval of the local ethics committees. Written informed consent was received from participants prior to inclusion in the study. All mouse experiments were conducted according to institutional and federal guidelines and approved by the LANUV NRW VSG 84-02.04.2013.A336.

Author contributions:

FB, LB, RAH, VGP, MNW, MR, DF, GGS, SK, MTL, WB performed experiments,;FB, LB, RAH, VGP, MNW, DF, MTL, WB, MGS analysed data; FB, VGP, PTB, CDC, MK, MGS, TBH, BSche, TB, BSchu, CEK conceived experiments, FB, VGP, BSchu, CEK wrote the manuscript, all authors revised the manuscript, all authors agreed on the publication in the presented state.

Conflict of interest:

The authors declare no conflict of interest.

Acknowledgments:

The excellent technical expertise of Martyna Brütting and Melanie Schaper is gratefully acknowledged. All schematics in figures were created with BioRender.com. The ERCB-KFB was supported by the Else Kröner-Fresenius Foundation. We also thank all participating centres of the European Renal cDNA Bank - Kröner-Fresenius biopsy bank (ERCB-KFB) and their patients for their cooperation. Active members at the time of the study see (N. Shved et al., Scientific reports 7, 8576 (2017)). The Nephrotic Syndrome Study Network Consortium (NEPTUNE), U54-DK-083912, is a part of the National Institutes of Health (NIH) Rare Disease Clinical Research Network (RDCRN), supported through a collaboration between the Office of Rare Diseases Research, National Center for Advancing Translational Sciences and the 
National Institute of Diabetes, Digestive, and Kidney Diseases. Additional funding and/or programmatic support for this project has also been provided by the University of Michigan, the NephCure Kidney International and the Halpin Foundation. The views expressed in written materials or publications do not necessarily reflect the official policies of the Department of Health and Human Services; nor does mention by trade names, commercial practices, or organizations imply endorsement by the U.S. Government.

Members of the Nephrotic Syndrome Study Network (NEPTUNE)

NEPTUNE Enrolling Centers

Cleveland Clinic, Cleveland, OH: K Dell ${ }^{*}$, J Sedor**, M Schachere\#, J Negrey\#

Children's Hospital, Los Angeles, CA: K Lemley*, E Lim\#

Children's Mercy Hospital, Kansas City, MO: T Srivastava*, A Garrett\#

Cohen Children's Hospital, New Hyde Park, NY: C Sethna*, K Laurent \#

Columbia University, New York, NY: P Canetta ${ }^{*}$, A Pradhan\#

Emory University, Atlanta, GA: L Greenbaum*, C Wang ${ }^{\star *}$, C Kang\#

Harbor-University of California Los Angeles Medical Center: S Adler*, J LaPage\#

John H. Stroger Jr. Hospital of Cook County, Chicago, IL: A Athavale*, M Itteera

Johns Hopkins Medicine, Baltimore, MD: M Atkinson*, S Boynton\#

Mayo Clinic, Rochester, MN: F Fervenza*, M Hogan**, J Lieske*, V Chernitskiy\#

Montefiore Medical Center, Bronx, NY: F Kaskel*, M Ross*, P Flynn\#

NIDDK Intramural, Bethesda MD: J Kopp*, J Blake\#

New York University Medical Center, New York, NY: H Trachtman*, O Zhdanova**, F Modersitzki\#, S Vento\#

Stanford University, Stanford, CA: R Lafayette*, K Mehta\#

Temple University, Philadelphia, PA: C Gadegbeku*, S Quinn-Boyle\#

University Health Network Toronto: M Hladunewich**, H Reich ${ }^{\star \star}$, P Ling\#, M Romano\#

University of Miami, Miami, FL: A Fornoni, C Bidot\#

University of Michigan, Ann Arbor, MI: M Kretzler*, D Gipson*, A Williams\#, J LaVigne\#

University of North Carolina, Chapel Hill, NC: V Derebail*, K Gibson*, E Cole\#, J Ormond-

Foster\#

University of Pennsylvania, Philadelphia, PA: L Holzman*, K Meyers**, K Kallem\#, A

Swenson\#

University of Texas Southwestern, Dallas, TX: K Sambandam*, Z Wang\#, M Rogers\#

University of Washington, Seattle, WA: A Jefferson*, S Hingorani**, K Tuttle ${ }^{\star \star} \S$, M Bray \#, M

Kelton\#, A Cooper\#§

Wake Forest University Baptist Health, Winston-Salem, NC: JJ Lin*, Stefanie Baker\# 
Data Analysis and Coordinating Center: M Kretzler, L Barisoni, J Bixler, H Desmond, S Eddy, D Fermin, C Gadegbeku, B Gillespie, D Gipson, L Holzman, V Kurtz, M Larkina, J Lavigne, S Li, S Li, CC Lienczewski, J Liu, T Mainieri, L Mariani, M Sampson, J Sedor, A Smith, A Williams, $\mathrm{J}$ Zee.

Digital Pathology Committee: Carmen Avila-Casado (University Health Network, Toronto), Serena Bagnasco (Johns Hopkins University), Joseph Gaut (Washington University in St Louis), Stephen Hewitt (National Cancer Institute), Jeff Hodgin (University of Michigan), Kevin Lemley (Children's Hospital of Los Angeles), Laura Mariani (University of Michigan), Matthew Palmer (University of Pennsylvania), Avi Rosenberg (Johns Hopkins University), Virginie Royal (University of Montreal), David Thomas (University of Miami), Jarcy Zee (University of Pennsylvania) Co-Chairs: Laura Barisoni (Duke University) and Cynthia Nast (Cedar Sinai).

${ }^{*}$ Principal Investigator; **Co-investigator; \#Study Coordinator

§Providence Medical Research Center, Spokane, WA

\section{References:}

Apelt, K., White, S.M., Kim, H.S., Yeo, J.-E., Kragten, A., Wondergem, A.P., Rooimans, M.A., González-Prieto, R., Wiegant, W.W., Lunke, S., et al. (2020). ERCC1 mutations impede DNA damage repair and cause liver and kidney dysfunction in patients. J Exp Med 218.

Braun, D.A., Rao, J., Mollet, G., Schapiro, D., Daugeron, M.-C., Tan, W., Gribouval, O., Boyer, O., Revy, P., Jobst-Schwan, T., et al. (2017). Mutations in KEOPS-complex genes cause nephrotic syndrome with primary microcephaly. Nature Genetics 49, 1529-1538.

Budanov, A.V., and Karin, M. (2008). p53 Target Genes Sestrin1 and Sestrin2 Connect Genotoxic Stress and mTOR Signaling. Cell 134, 451-460.

Butani, L. (2004). Investigation of Pediatric Renal Transplant Recipients with Heavy Proteinuria after Sirolimus Rescue. Transplantation 78, 1362-1366.

Butt, L., Unnersjö-Jess, D., Höhne, M., Edwards, A., Binz-Lotter, J., Reilly, D., Hahnfeldt, R., Ziegler, V., Fremter, K., Rinschen, M.M., et al. (2020). A molecular mechanism explaining albuminuria in kidney disease. Nat Metabolism 2, 461-474.

Chatterjee, N., and Walker, G.C. (2017). Mechanisms of DNA damage, repair, and mutagenesis: DNA Damage and Repair. Environ Mol Mutagen 58, 235-263.

Chebel, A., Catallo, R., Mabon, C., Bachy, E., Wenner, T., Salles, G., Pouteil-Noble, C., and Ffrench, M. (2016). Rapamycin safeguards lymphocytes from DNA damage accumulation in vivo. European Journal of Cell Biology 95, 331-341.

Chehida, A.B., Ghali, N., Abdelaziz, R.B., Moussa, F.B., and Tebib, N. (2017). Renal Involvement in 2 Siblings With Cockayne Syndrome. Iran J Kidney Dis 11, 253-255.

Chen, T.K., Knicely, D.H., and Grams, M.E. (2019). Chronic Kidney Disease Diagnosis and Management. Jama 322, 1294-1304.

Cho, M.E., Hurley, J.K., and Kopp, J.B. (2007). Sirolimus Therapy of Focal Segmental Glomerulosclerosis Is Associated With Nephrotoxicity. Am J Kidney Dis 49, 310-317. 
Dittrich, E., Schmaldienst, S., Soleiman, A., Horl, W.H., and Pohanka, E. (2004). Rapamycinassociated post-transplantation glomerulonephritis and its remission after reintroduction of calcineurin-inhibitor therapy. Transplant Int 17, 215-220.

Doig, J., Anderson, C., Lawrence, N.J., Selfridge, J., Brownstein, D.G., and Melton, D.W. (2006). Mice with skin-specific DNA repair gene (Ercc1) inactivation are hypersensitive to ultraviolet irradiation-induced skin cancer and show more rapid actinic progression.

Oncogene 25, 6229-6238.

Dominick, G., Bowman, J., Li, X., Miller, R.A., and Garcia, G.G. (2016). mTOR regulates the expression of DNA damage response enzymes in long-lived Snell dwarf, GHRKO, and PAPPA-KO mice. Aging Cell 16, 52-60.

Endlich, N., Kliewe, F., Kindt, F., Schmidt, K., Kotb, A.M., Artelt, N., Lindenmeyer, M.T., Cohen, C.D., Döring, F., Kuss, A.W., et al. (2018). The transcription factor Dach1 is essential for podocyte function. J Cell Mol Med 22, 2656-2669.

Faridounnia, M., Wienk, H., Kovačič, L., Folkers, G.E., Jaspers, N.G.J., Kaptein, R., Hoeijmakers, J.H.J., and Boelens, R. (2015). The Cerebro-Oculo-Facio-Skeletal (COFS) Syndrome point mutation F231L in the ERCC1 DNA repair protein causes dissociation of the ERCC1-XPF complex. Journal of Biological Chemistry.

Ghosal, G., and Chen, J. (2013). DNA damage tolerance: a double-edged sword guarding the genome. Transl Cancer Res 2, 107-129.

Gödel, M., Hartleben, B., Herbach, N., Liu, S., Zschiedrich, S., Lu, S., Debreczeni-Mór, A., Lindenmeyer, M.T., Rastaldi, M.-P., Hartleben, G., et al. (2011). Role of mTOR in podocyte function and diabetic nephropathy in humans and mice. The Journal of Clinical Investigation 121, 2197-2209.

Hakroush, S., Cebulla, A., Schaldecker, T., Behr, D., Mundel, P., and Weins, A. (2014). Extensive Podocyte Loss Triggers a Rapid Parietal Epithelial Cell Response. Journal of the American Society of Nephrology: JASN 25, 927-938.

Hayashi, K., Hishikawa, A., Hashiguchi, A., Azegami, T., Yoshimoto, N., Nakamichi, R., Tokuyama, H., and Itoh, H. (2020). Association of glomerular DNA damage and DNA methylation with one-year eGFR decline in IgA nephropathy. Sci Rep-Uk 10, 237.

Hecker, A., Graille, M., Madec, E., Gadelle, D., Le Cam, E., van Tilbergh, H., and Forterre, P. (2009). The universal Kae1 protein and the associated Bud32 kinase (PRPK), a mysterious protein couple probably essential for genome maintenance in Archaea and Eukarya. Biochem Soc T 37, 29-35.

Hirooka, M., Hirota, M., and Kamada, M. (1988). Renal lesions in Cockayne syndrome. Pediatr Nephrol 2, 239-243.

Hishikawa, A., Hayashi, K., Abe, T., Kaneko, M., Yokoi, H., Azegami, T., Nakamura, M., Yoshimoto, N., Kanda, T., Sakamaki, Y., et al. (2019). Decreased KAT5 Expression Impairs DNA Repair and Induces Altered DNA Methylation in Kidney Podocytes. Cell Reports 26, 1318-1332.e4.

Hishikawa, A., Hayashi, K., Yoshimoto, N., Nakamichi, R., Homma, K., and Itoh, H. (2020). DNA damage and expression of DNA methylation modulators in urine-derived cells of patients with hypertension and diabetes. Sci Rep-Uk 10, 3377.

Hochegger, K., Jansky, G.L., Soleiman, A., Wolf, A.M., Tagwerker, A., Seger, C., Griesmacher, A., Mayer, G., and Rosenkranz, A.R. (2008). Differential Effects of Rapamycin in Anti-GBM Glomerulonephritis. J Am Soc Nephrol 19, 1520-1529.

Inoki, K., Mori, H., Wang, J., Suzuki, T., Hong, S., Yoshida, S., Blattner, S.M., Ikenoue, T., Rüegg, M.A., Hall, M.N., et al. (2011). mTORC1 activation in podocytes is a critical step in 
the development of diabetic nephropathy in mice. The Journal of Clinical Investigation 121, 2181-2196.

Ising, C., Koehler, S., Brähler, S., Merkwirth, C., Höhne, M., Baris, O.R., Hagmann, H., Kann, M., Fabretti, F., Dafinger, C., et al. (2015). Inhibition of insulin/IGF-1 receptor signaling protects from mitochondria-mediated kidney failure. EMBO Molecular Medicine 7, 275-287.

Izzedine, H., Brocheriou, I., and Frances, C. (2005). Post-Transplantation Proteinuria and Sirolimus. New Engl J Med 353, 2088-2089.

Karakasilioti, I., Kamileri, I., Chatzinikolaou, G., Kosteas, T., Vergadi, E., Robinson, A.R., Tsamardinos, I., Rozgaja, T.A., Siakouli, S., Tsatsanis, C., et al. (2013). DNA Damage Triggers a Chronic Autoinflammatory Response, Leading to Fat Depletion in NER Progeria. Cell Metabolism 18, 403-415.

Kondo, D., Noguchi, A., Tamura, H., Tsuchida, S., Takahashi, I., Kubota, H., Yano, T., Oyama, C., Sawaishi, Y., Moriwaki, S., et al. (2016). Elevated Urinary Levels of 8-Hydroxy2'-deoxyguanosine in a Japanese Child of Xeroderma Pigmentosum/Cockayne Syndrome Complex with Infantile Onset of Nephrotic Syndrome. Tohoku J Exp Medicine 239, 231-235.

Kurayama, R., Ito, N., Nishibori, Y., Fukuhara, D., Akimoto, Y., Higashihara, E., Ishigaki, Y., Sai, Y., Miyamoto, K., Endou, H., et al. (2011). Role of amino acid transporter LAT2 in the activation of mTORC1 pathway and the pathogenesis of crescentic glomerulonephritis. Lab Invest 91, 992-1006.

Letavernier, E., Bruneval, P., Mandet, C., Huyen, J.-P.D.V., Péraldi, M.-N., Helal, I., Noël, L.H., and Legendre, C. (2007). High Sirolimus Levels May Induce Focal Segmental Glomerulosclerosis De Novo. Clin J Am Soc Nephro 2, 326-333.

Liebau, M.C., Braun, F., Höpker, K., Weitbrecht, C., Bartels, V., Müller, R.-U., Brodesser, S., Saleem, M.A., Benzing, T., Schermer, B., et al. (2013). Dysregulated Autophagy Contributes to Podocyte Damage in Fabry's Disease. Plos One 8, e63506.

Lindahl, T., and Nyberg, B. (1972). Rate of depurination of native deoxyribonucleic acid. Biochemistry-Us 11, 3610-3618.

Loeb, L.A., and Harris, C.C. (2008). Advances in chemical carcinogenesis: a historical review and prospective. Cancer Res 68, 6863-6872.

Madabhushi, R., Pan, L., and Tsai, L.-H. (2014). DNA damage and its links to neurodegeneration. Neuron 83, 266-282.

Marshall, C.B., Pippin, J.W., Krofft, R.D., and Shankland, S.J. (2006). Puromycin aminonucleoside induces oxidant-dependent DNA damage in podocytes in vitro and in vivo. Kidney Int 70, 1962-1973.

Milanese, C., Bombardieri, C.R., Sepe, S., Barnhoorn, S., Payán-Goméz, C., Caruso, D., Audano, M., Pedretti, S., Vermeij, W.P., Brandt, R.M.C., et al. (2019). DNA damage and transcription stress cause ATP-mediated redesign of metabolism and potentiation of antioxidant buffering. Nat Commun 10, 4887.

Moeller, M.J., Sanden, S.K., Soofi, A., Wiggins, R.C., and Holzman, L.B. (2003). Podocytespecific expression of cre recombinase in transgenic mice. Genesis (New York, N.Y. : 2000) 35, 39-42.

Mulderrig, L., and Garaycoechea, J.I. (2020). XPF-ERCC1 protects liver, kidney and blood homeostasis outside the canonical excision repair pathways. Plos Genet 16, e1008555.

Niedernhofer, L.J., Garinis, G.A., Raams, A., Lalai, A.S., Robinson, A.R., Appeldoorn, E., Odijk, H., Oostendorp, R., Ahmad, A., Leeuwen, W. van, et al. (2006). A new progeroid syndrome reveals that genotoxic stress suppresses the somatotroph axis. Nature 444, 10381043. 
Nishizono, R., Kikuchi, M., Wang, S.Q., Chowdhury, M., Nair, V., Hartman, J., Fukuda, A., Wickman, L., Hodgin, J.B., Bitzer, M., et al. (2017). FSGS as an Adaptive Response to Growth-Induced Podocyte Stress. Journal of the American Society of Nephrology: JASN 28, 2931-2945.

Puelles, V.G., Douglas-Denton, R.N., Cullen-McEwen, L.A., Li, J., Hughson, M.D., Hoy, W.E., Kerr, P.G., and Bertram, J.F. (2015). Podocyte Number in Children and Adults: Associations with Glomerular Size and Numbers of Other Glomerular Resident Cells. J Am Soc Nephrol 26, 2277-2288.

Puelles, V.G., Wolde, J.W. van der, Wanner, N., Scheppach, M.W., Cullen-McEwen, L.A., Bork, T., Lindenmeyer, M.T., Gernhold, L., Wong, M.N., Braun, F., et al. (2019). mTORmediated podocyte hypertrophy regulates glomerular integrity in mice and humans. Jci Insight 4, e99271.

Reiling, J.H., and Hafen, E. (2004). The hypoxia-induced paralogs Scylla and Charybdis inhibit growth by down-regulating S6K activity upstream of TSC in Drosophila. Gene Dev 18, 2879-2892.

Rinschen, M.M., Gödel, M., Grahammer, F., Zschiedrich, S., Helmstädter, M., Kretz, O., Zarei, M., Braun, D.A., Dittrich, S., Pahmeyer, C., et al. (2018). A Multi-layered Quantitative In Vivo Expression Atlas of the Podocyte Unravels Kidney Disease Candidate Genes. Cell Reports 23, 2495-2508.

Rosenberg, A.Z., and Kopp, J.B. (2017). Focal Segmental Glomerulosclerosis. Clinical Journal of the American Society of Nephrology: CJASN 12, 502-517.

Schermer, B., Bartels, V., Frommolt, P., Habermann, B., Braun, F., Schultze, J.L., Roodbergen, M., Hoeijmakers, J.H., Schumacher, B., Nürnberg, P., et al. (2013).

Transcriptional profiling reveals progeroid $E r c c 1-/ \Delta$ mice as a model system for glomerular aging. Bmc Genomics 14, 559.

Sennesael, J.J., Bosmans, J.L., Bogers, J.P., Verbeelen, D., and Verpooten, G.A. (2005). Conversion from Cyclosporine to Sirolimus in Stable Renal Transplant Recipients. Transplantation 80, 1578-1585.

Settembre, C., Fraldi, A., Medina, D.L., and Ballabio, A. (2013). Signals from the lysosome: a control centre for cellular clearance and energy metabolism. Nature Reviews Molecular Cell Biology 14, 283-296.

Shankland, S.J., Pippin, J.W., Reiser, J., and Mundel, P. (2007). Podocytes in culture: past, present, and future. Kidney International 72, 26-36.

Wanner, N., Hartleben, B., Herbach, N., Goedel, M., Stickel, N., Zeiser, R., Walz, G., Moeller, M.J., Grahammer, F., and Huber, T.B. (2014). Unraveling the role of podocyte turnover in glomerular aging and injury. Journal of the American Society of Nephrology: JASN 25, 707-716.

Wolters, S., and Schumacher, B. (2013). Genome maintenance and transcription integrity in aging and disease. Frontiers Genetics 4, 19.

Wu, D.-D., Gao, Y.-R., Li, T., Wang, D.-Y., Lu, D., Liu, S.-Y., Hong, Y., Ning, H.-B., Liu, J.-P., Shang, J., et al. (2018). PEST-containing nuclear protein mediates the proliferation, migration, and invasion of human neuroblastoma cells through MAPK and PI3K/AKT/mTOR signaling pathways. Bmc Cancer 18, 499.

Xie, X., Hu, H., Tong, X., Li, L., Liu, X., Chen, M., Yuan, H., Xie, X., Li, Q., Zhang, Y., et al. (2018). The mTOR-S6K pathway links growth signalling to DNA damage response by targeting RNF168. Nat Cell Biol 20, 320-331. 
bioRxiv preprint doi: https://doi.org/10.1101/2020.09.13.295303; this version posted January 1, 2021. The copyright holder for this preprint

(which was not certified by peer review) is the author/funder, who has granted bioRxiv a license to display the preprint in perpetuity. It is made available under aCC-BY-ND 4.0 International license.

Zschiedrich, S., Bork, T., Liang, W., Wanner, N., Eulenbruch, K., Munder, S., Hartleben, B., Kretz, O., Gerber, S., Simons, M., et al. (2017). Targeting mTOR Signaling Can Prevent the Progression of FSGS. Journal of the American Society of Nephrology: JASN 28, 2144-2157. 
Figures and Figure Legends:

A

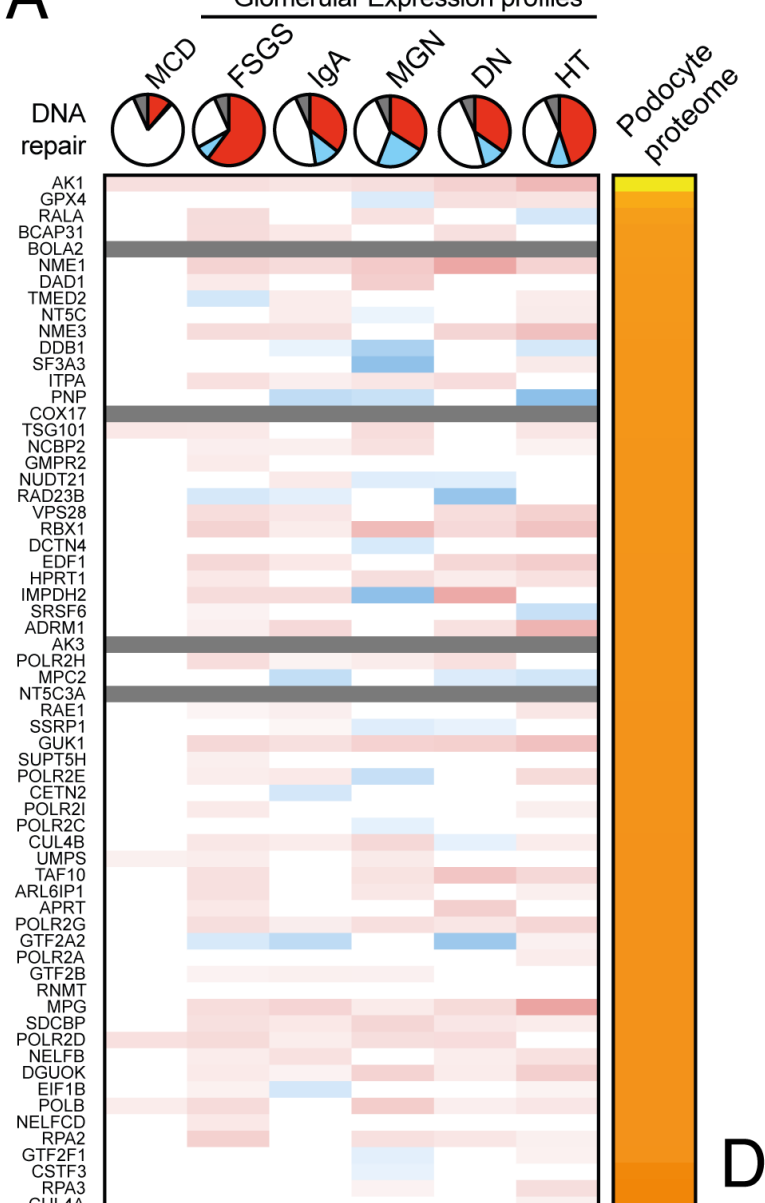

D

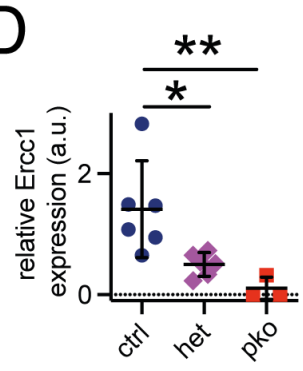

B

C
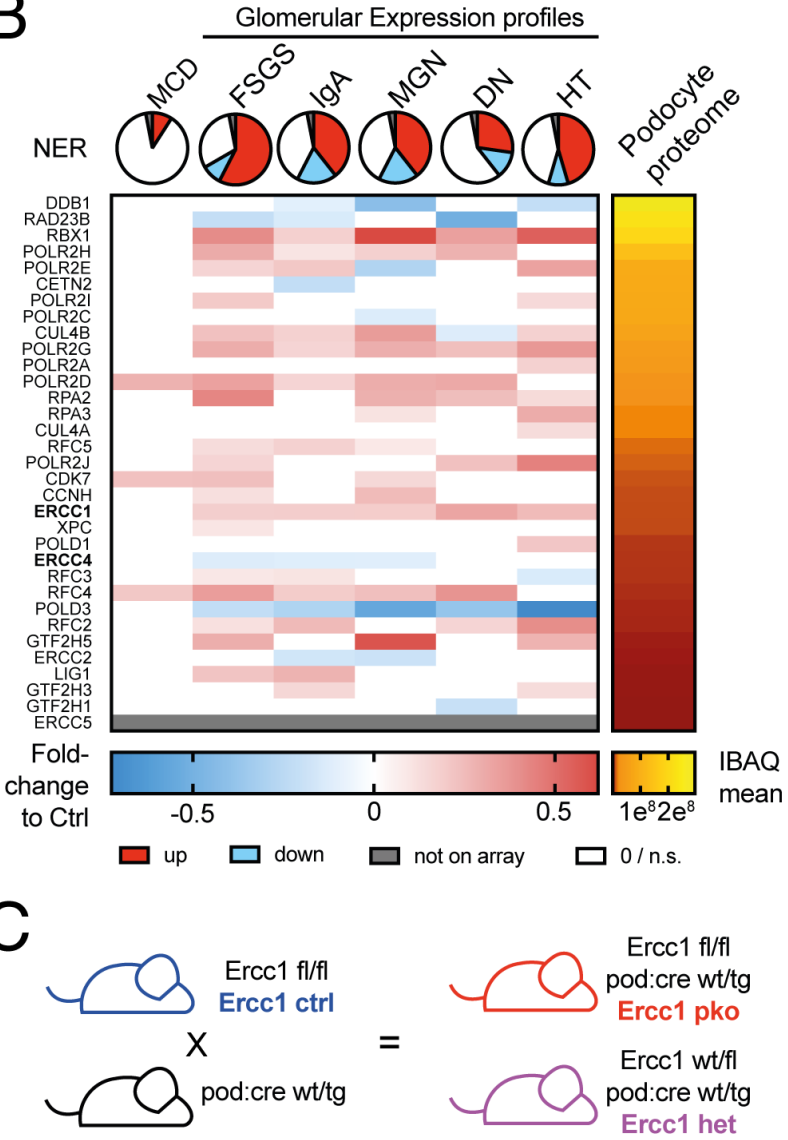

$E$

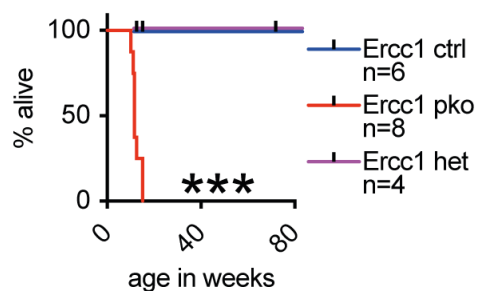

F

36 weeks

G Ercc1 het $72 w$

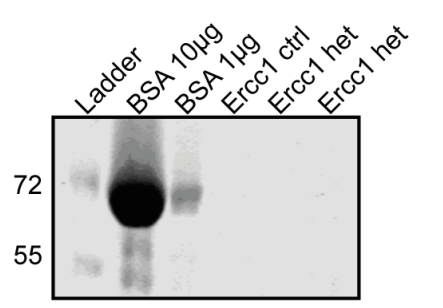

$\mathrm{H}$

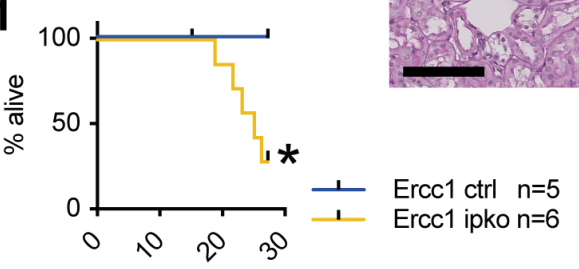

weeks since Tamoxifen induction

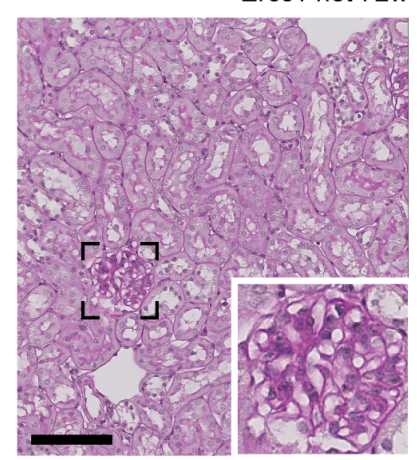


bioRxiv preprint doi: https://doi.org/10.1101/2020.09.13.295303; this version posted January 1,2021 . The copyright holder for this preprint

(which was not certified by peer review) is the author/funder, who has granted bioRxiv a license to display the preprint in perpetuity. It is made available under aCC-BY-ND 4.0 International license.

\section{Figure S1:}

A: Expression profile of 118 hallmark DNA repair and 33 B: NER genes in MCD, FSGS, IgA Nephropathy (IgA), membranous glomerulonephritis (MGN), diabetic nephropathy (DN) and hypertension (HT) glomeruli compared to controls depicted as parts of a whole and single genes in heatmaps.

C: Breeding scheme for homozygous and heterozygous podocyte-specific Ercc1 ko mice.

D: qPCR analysis for Ercc1 in FACsorted podocytes of Ercc1 ctrl, wt/pko or pko mice. Delta-Delta-CT values expressed as scatterplots depicting mean plus $95 \%$ confidence interval,

E: Kaplan-Meyer curve depicting survival of ctrl, het and pko mice (Mantel-Cox-Test).

F: Representative Coomassie blue staining of Ercc1 ctrl and wt/pko urine at 36 weeks of age, bovine serum albumin (BSA) was loaded as reference.

G: Representative Periodic Acid Schiff (PAS) staining of Ercc1 wt/pko kidney at 36 weeks of age.

$\mathrm{H}$ : Kaplan-Meyer curve depicting survival of Ercc1 ctrl and ipko mice (Mantel-Cox-Test).

${ }^{*} p \leq 0,05,{ }^{* *} p \leq 0,01,{ }^{* *} p \leq 0,001$, scalebar: $100 \mu \mathrm{m}$. 


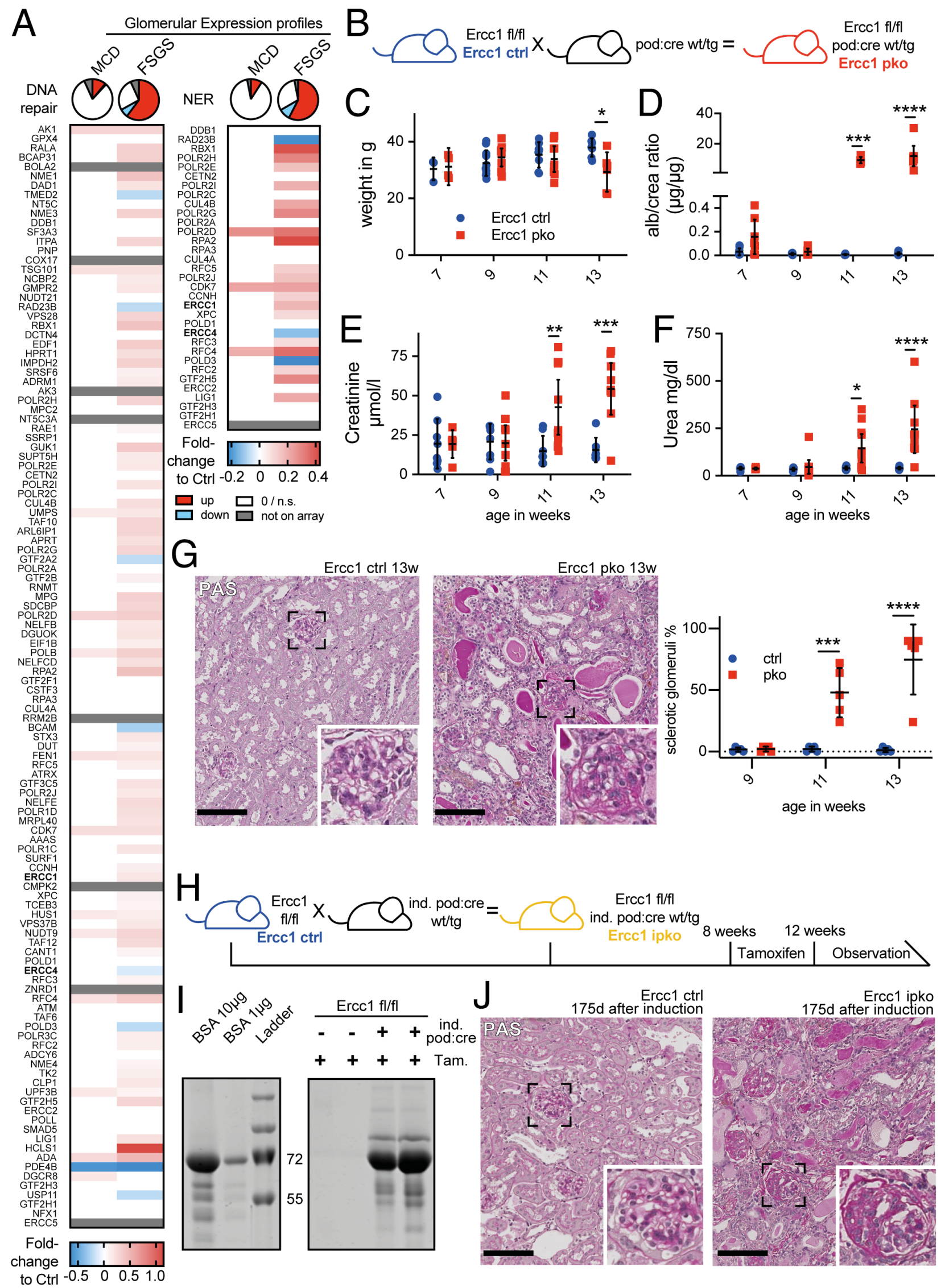

Figure 1: Nucleotide excision repair gene expression is perturbed in FSGS and essential for podocytes health.

A: Expression profile of 118 hallmark DNA repair and 33 NER genes in FSGS and MCD glomeruli compared to controls depicted as parts of a whole (circles) and single genes (columns) in heatmaps. 
bioRxiv preprint doi: https://doi.org/10.1101/2020.09.13.295303; this version posted January 1,2021 . The copyright holder for this preprint (which was not certified by peer review) is the author/funder, who has granted bioRxiv a license to display the preprint in perpetuity. It is made available under aCC-BY-ND 4.0 International license.

B: Breeding scheme for homozygous podocyte-specific constitutive Ercc1 ko mice (pko).

C: Weight analysis; D: urinary albumin/creatinine analysis; E: serum creatinine analysis; F: serum urea analysis of Ercc1 ctrl and pko mice.

G: Representative Periodic Acid Schiff (PAS) staining of 13 week-old Ercc1 ctrl and pko mice and quantification of sclerotic glomeruli, $n=5,50$ glomeruli per sample.

$\mathrm{H}$ : Breeding and induction scheme for homozygous inducible podocyte specific Ercc1 ko mice (ipko).

I: Representative Coomassie blue staining of Ercc1 ctrl and ipko urine 124d after induction with tamoxifen, bovine serum albumin (BSA) was loaded as reference $(n=6)$.

J: Representative Periodic Acid Schiff (PAS) staining of Ercc1 ctrl and ipko mice 175d after induction with tamoxifen $(n=6)$.

All scatterplots indicate mean plus $95 \%$ confidence interval, ${ }^{*} p \leq 0,05,{ }^{* *} p \leq 0,01,{ }^{* \star *} p \leq 0,001,{ }^{* \star * *} p \leq$ 0,0001 , scalebars: $100 \mu \mathrm{m}$. 
A
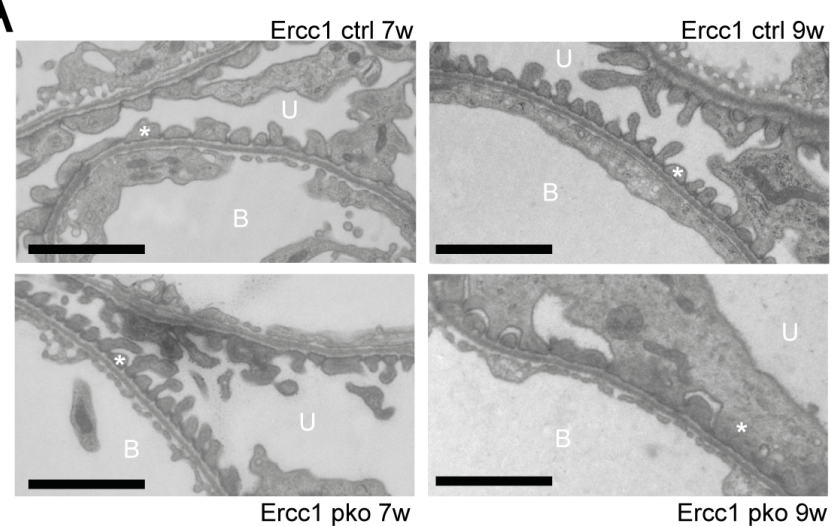

C

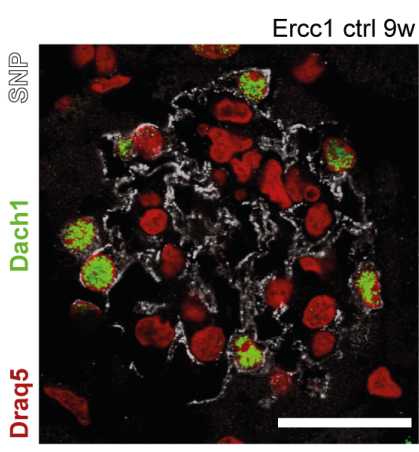

$\mathrm{E}$

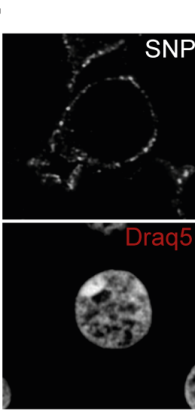

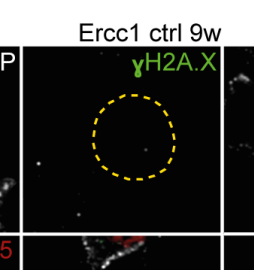

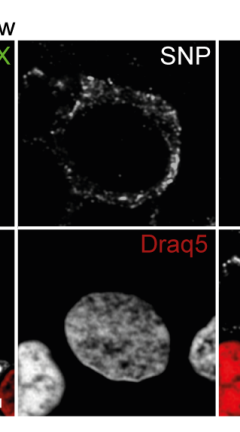

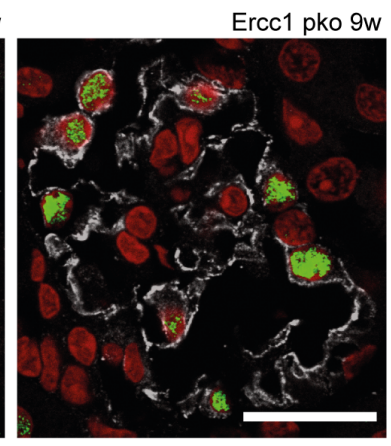

B
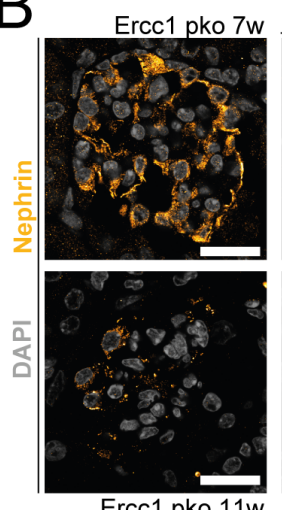

Ercc1 pko 11w
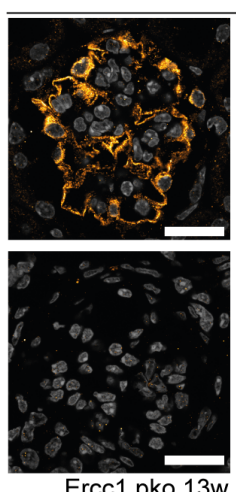

Ercc1 pko 13w

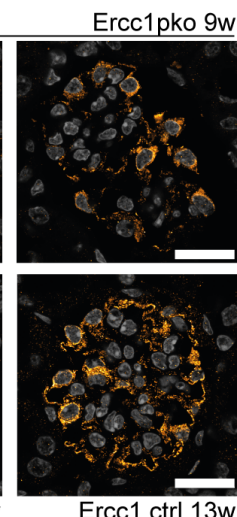

D
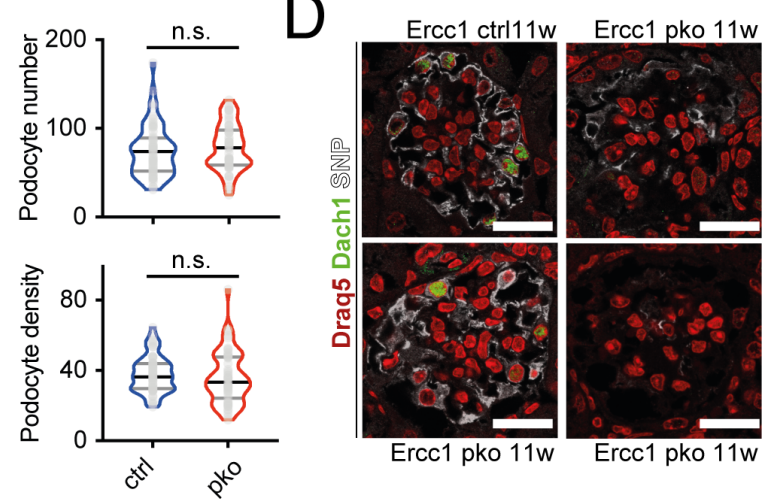

$\mathrm{F}$

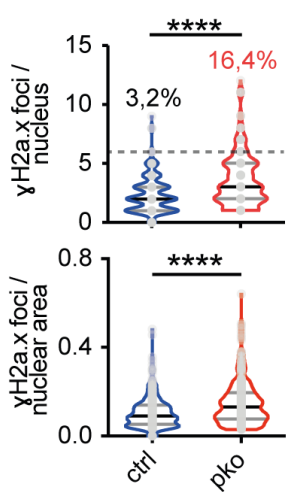

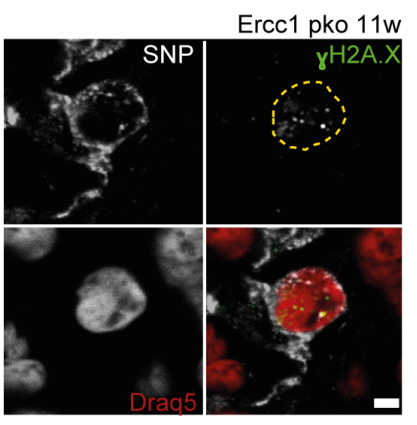

Figure 2: The podocyte-specific constitutive ko of Ercc1 leads to foot process effacement and podocyte loss accompanied by accumulation of DNA damage.

A: Representative electron microscopy image of 7 and 9 week-old Ercc1 $\mathrm{ctrl}$ and pko podocyte, scalebar indicating $2 \mu \mathrm{m}$, B: blood side - intracapillary space, U: urinary side - bowman's space, Asterix indicating podocyte foot process $(n=3)$.

B: Representative immunofluorescence staining of slit diaphragm protein nephrin with nuclear marker DAPI of Ercc1 ctrl and pko kidneys, scalebar indicating $2 \mu \mathrm{m}(n=5)$.

C: Representative immunofluorescence staining of podocyte proteins synaptopodin (gray), Dachshund homolog 1 (dach1) (Endlich et al., 2018) (green) and far-red fluorescent DNA dye Draq5 (red) as a nuclear marker in sections of 9 week-old Ercc1 ctrl and pko kidneys, with quantification of podocyte number and density of Ercc1 ctrl and pko kidneys, scalebar indicating $10 \mu \mathrm{m}(\mathrm{n}=5)$.

D: corresponding staining in paraffin embedded sections of 11 week-old Ercc1 ctrl and pko kidneys, scalebar indicating $10 \mu \mathrm{m}(\mathrm{n}=5)$.

$\mathrm{E}$ : Representative immunofluorescence staining of synaptopodin (gray), DNA damage marker $\mathrm{YH} 2 \mathrm{~A} . \mathrm{X}$ (green) and nuclear marker Draq5 (red) in sections of 9 week-old Ercc1 ctrl and pko kidneys, with quantification of $\mathrm{YH} 2 \mathrm{~A} . \mathrm{X}$ foci per podocyte nucleus and nuclear area of Ercc1 ctrl and pko kidneys, 
bioRxiv preprint doi: https://doi.org/10.1101/2020.09.13.295303; this version posted January 1,2021 . The copyright holder for this preprint

(which was not certified by peer review) is the author/funder, who has granted bioRxiv a license to display the preprint in perpetuity. It is made available under aCC-BY-ND 4.0 International license.

scalebar indicating $2 \mu \mathrm{m}$, yellow dotted line indicating nuclear border $(n=5,10$ glomeruli per sample, 5 podocytes per glomerulus).

F: Staining corresponding to Fig 2E in paraffin-embedded sections of 11 week-old Ercc1 ctrl and pko kidneys, scalebar indicating $2 \mu \mathrm{m}$, yellow dotted line indicating nuclear border $(n=5)$.

All violin plots indicate median (black) and upper and lower quartile (gray), ${ }^{* \star *} p \leq 0,001,{ }^{* \star *} p \leq 0,0001$. 

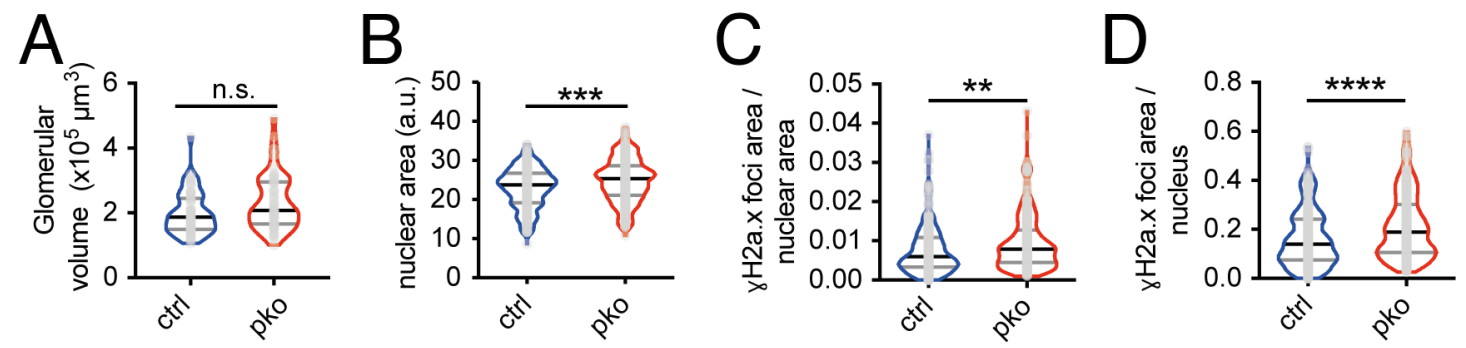

\section{Figure S2:}

A: Quantification of glomerular volume of 9 week-old Ercc1 ctrl and pko kidneys ( $n=5,10$ glomeruli per sample)

B: Quantification of podocyte nuclear area of 9 week-old Ercc1 ctrl and pko kidneys, $n=5,10$ glomeruli per sample, 5 podocytes per glomerulus.

C: Quantification of $\mathrm{YH} 2 \mathrm{~A} . \mathrm{X}$ foci area per podocyte nuclear area of 9 week-old Ercc1 ctrl and pko kidneys, $n=5,10$ glomeruli per sample, 5 podocytes per glomerulus.

D: Quantification of $\mathrm{YH} 2 \mathrm{~A}$.X foci area per podocyte nucleus of 9 week-old Ercc1 ctrl and pko kidneys, $n$ $=5,10$ glomeruli per sample, 5 podocytes per glomerulus.

All violin plots indicate median (black) and upper and lower quartile (gray), ${ }^{* *} p \leq 0,01,{ }^{* * *} p \leq 0,001,{ }^{* * *} p$ $\leq 0,0001$ 

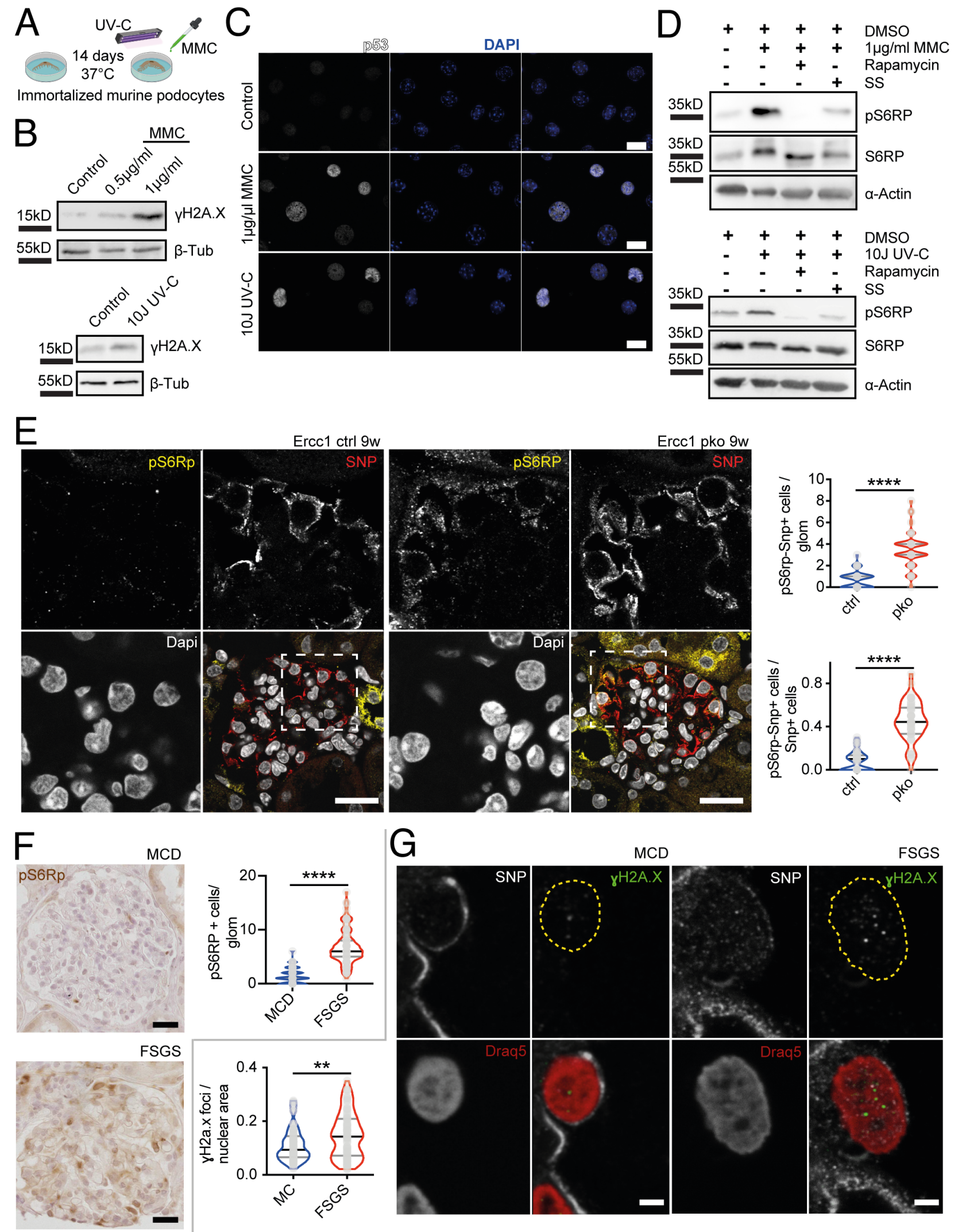

G
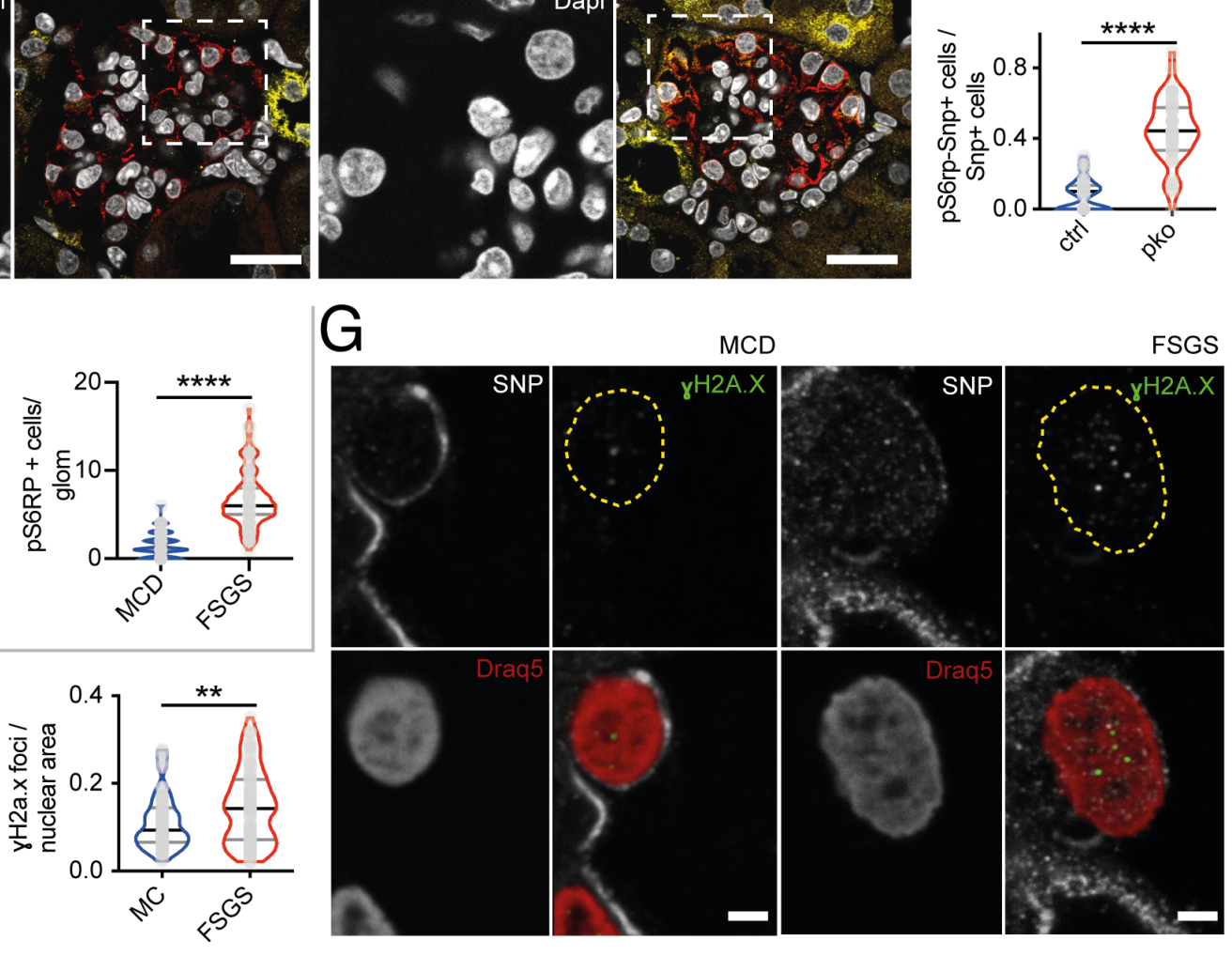

Figure 3: DNA damage leads to an activation of the mTORC1 pathway and is increased in human FSGS.

A: Schematic of in vitro protocol for the induction of DNA damage.

B: Representative immunoblot images for DNA damage marker $\mathrm{YH} 2 \mathrm{~A} . \mathrm{X}$ and loading control protein beta-tubulin of immortalized murine podocyte lysates $(n=3)$.

C: Representative immunofluorescence images for tumor suppressor p53 and nuclear marker DAPI in immortalized murine podocyte lysates $(n=3)$. 
bioRxiv preprint doi: https://doi.org/10.1101/2020.09.13.295303; this version posted January 1, 2021. The copyright holder for this preprint (which was not certified by peer review) is the author/funder, who has granted bioRxiv a license to display the preprint in perpetuity. It is made available under aCC-BY-ND 4.0 International license.

D: Representative immunoblot images for mTORC1 target phospho-S6-Ribosomal-Protein (pS6Rp), S6Rp and loading control protein alpha-actin of immortalized murine podocyte lysates $(n=3)$.

All cells imaged or lysed after treatment with mitomycin $C(M M C)$ or ultraviolet $C(U V-C)$ irradiation \pm Rapamycin or serum starvation (SS), $n \geq 4$.

$\mathrm{E}$ : Representative immunofluorescence staining of SNP, pS6Rp and DAPI in sections of 9 week-old Ercc1 ctrl and pko kidneys with Quantification of SNP and pS6Rp double positive cells per glomerulus and per total SNP positive cells, scalebar indicating $10 \mu \mathrm{m}(\mathrm{n}=5,10$ glomeruli per sample).

F: Representative immunohistochemistry staining of pS6Rp in sections of human MCD and FSGS biopsies with quantification of pS6Rp positive cells per glomerulus, scalebar indicating $25 \mu \mathrm{m}$ ( $n=4, \geq 72$ glomeruli per group),

G: Representative immunofluorescence staining of SNP, $\mathrm{YH} 2 \mathrm{~A} . \mathrm{X}$ and Draq5 in sections of human MCD and FSGS biopsies with quantification of $\mathrm{YH} 2 \mathrm{~A} . \mathrm{X}$ foci per podocyte nucleus scalebar indicating $2 \mu \mathrm{m}$, yellow dotted line indicating nuclear border ( $n=4,4$ glomeruli per sample, 5 podocytes per glomerulus). All violin plots indicating median (black) and upper and lower quartile (gray), ${ }^{* *} p \leq 0,01,{ }^{* * *} p \leq 0,001$, $* * * * p \leq 0,0001$. 


\section{Figure S3:}

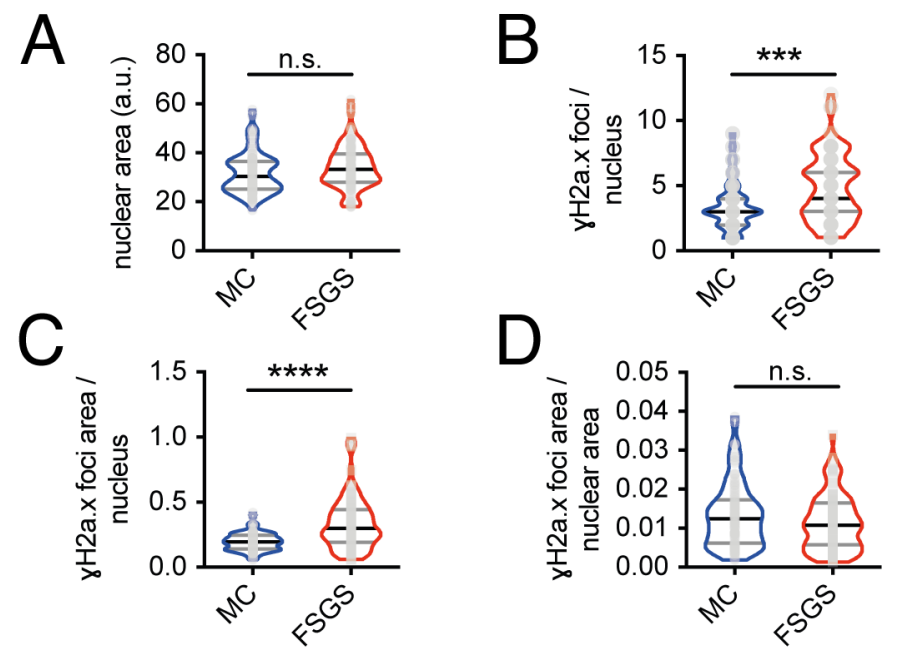

A: Quantification of podocyte nuclear area of human MCD and FSGS biopsies ( $n=4,4$ glomeruli per sample, 5 podocytes per glomerulus).

B: Quantification of $\mathrm{YH} 2 \mathrm{~A}$.X foci number per podocyte nucleus of human MCD and FSGS biopsies $(n=4$, 4 glomeruli per sample, 5 podocytes per glomerulus).

C: Quantification of $\mathrm{YH} 2 \mathrm{~A}$.X foci area per podocyte nucleus of human MCD and FSGS biopsies, $(n=4$, 4 glomeruli per sample, 5 podocytes per glomerulus).

D: Quantification of $\mathrm{YH} 2 \mathrm{~A} . \mathrm{X}$ foci area per podocyte nuclear area of human MCD and FSGS biopsies, ( $n=4,4$ glomeruli per sample, 5 podocytes per glomerulus).

All violin plots indicate median (black) and upper and lower quartile (gray), ${ }^{* *} p \leq 0,001,{ }^{* * *} p \leq 0,0001$ 


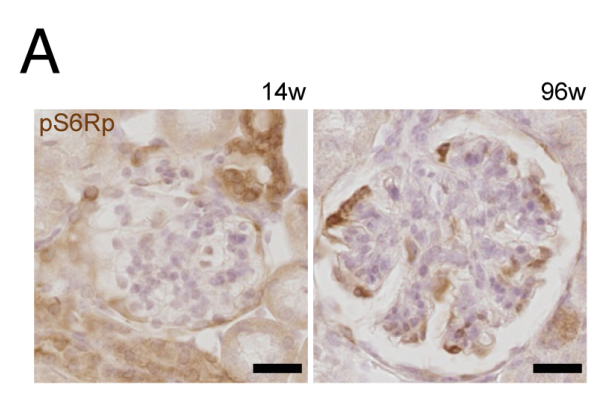

E

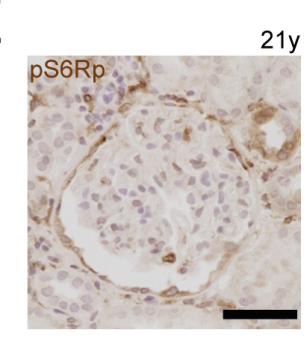

$21 y$

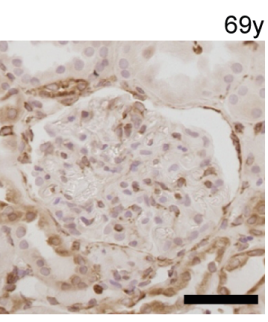

$69 y$
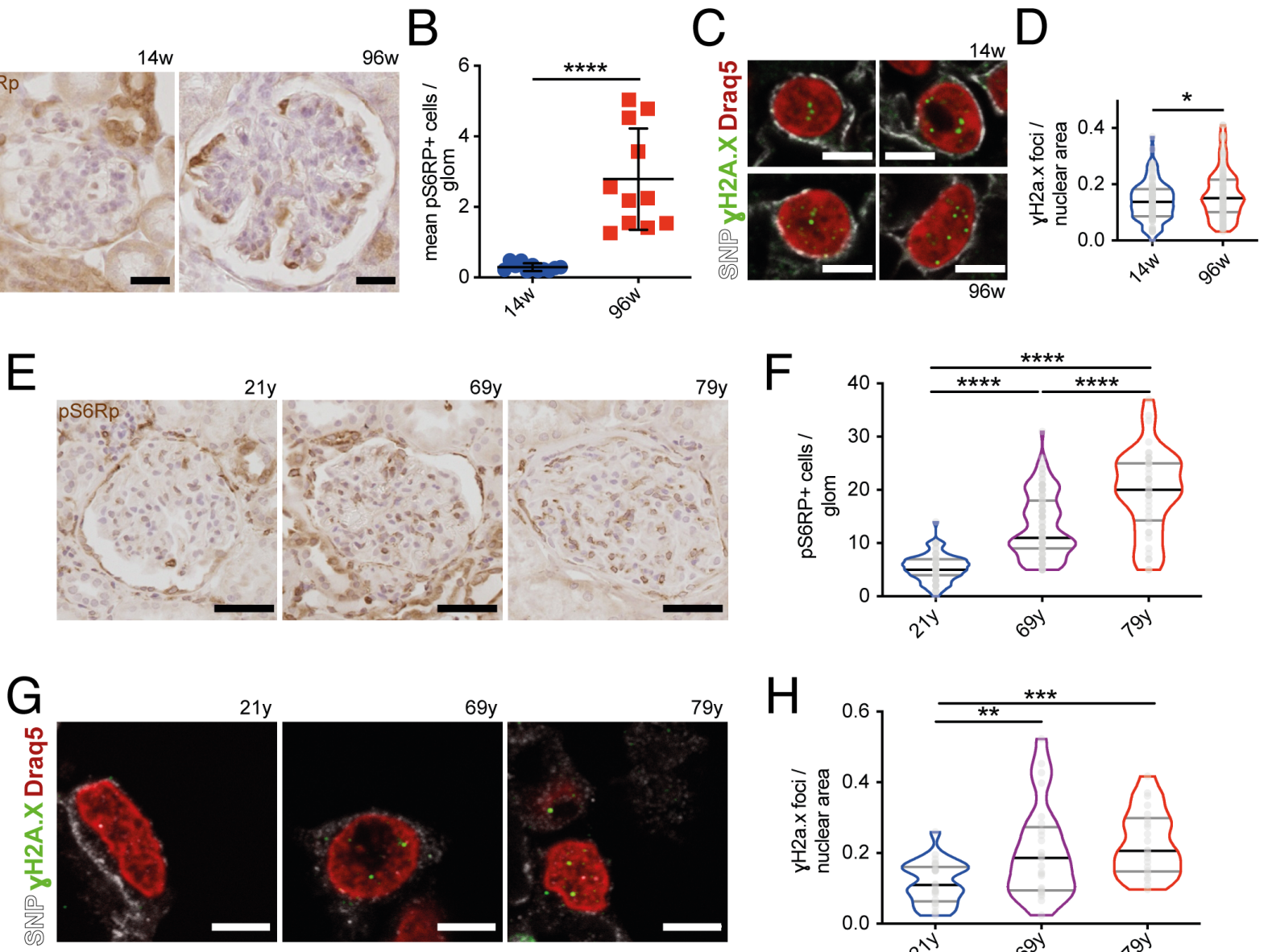

$\mathrm{H}$
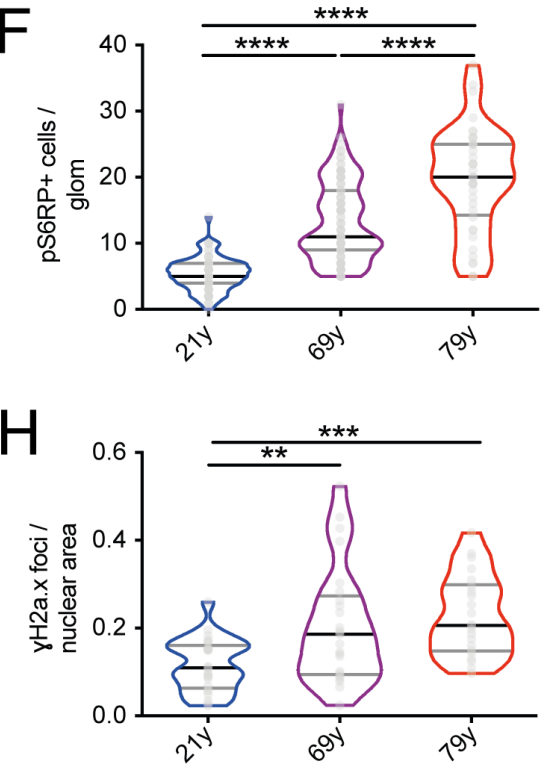

Figure S4:

A \& B: Representative immunohistochemistry staining of pS6Rp in sections of murine young and aged wildtype kidneys with quantification of pS6Rp-positive cells per glomerulus, scalebar indicating $25 \mu \mathrm{m}$ (n $=11,50$ glomeruli per sample).

C \& D: Representative immunofluorescence staining of SNP, $\mathrm{YH} 2 \mathrm{~A} . \mathrm{X}$ and Draq5 in sections of murine young and aged wildtype kidneys with quantification of $\mathrm{YH} 2 \mathrm{~A} . \mathrm{X}$ foci per podocyte nucleus, scalebar indicating $2 \mu \mathrm{m}$ ( $n=4,5$ glomeruli per sample, 5 podocytes per glomerulus).

E \& F: Representative immunohistochemistry staining of pS6Rp in sections of human young and aged kidneys with quantification of pS6Rp-positive cells per glomerulus, scalebar indicating $50 \mu \mathrm{m}(\geq 40$ glomeruli per sample).

G \& H: Representative immunofluorescence staining of SNP, $\mathrm{YH} 2 \mathrm{~A} . \mathrm{X}$ and Draq5 in sections of human young and aged kidneys with quantification of $\mathrm{YH} 2 \mathrm{~A} . \mathrm{X}$ foci per podocyte nucleus, scalebar indicating $5 \mu \mathrm{m}$ (5 glomeruli per sample, 5 podocytes per glomerulus).

Scatterplot depicting mean and $95 \%$ confidence interval, All violin plots indicating median (black) and upper and lower quartile (gray), ${ }^{\star} p \leq 0,05,{ }^{* *} p \leq 0,01,{ }^{* \star *} p \leq 0,001,{ }^{* \star \star *} p \leq 0,0001$. 
bioRxiv preprint doi: https://doi.org/10.1101/2020.09.13.295303; this version posted January 1, 2021. The copyright holder for this preprint (which was not certified by peer review) is the author/funder, who has granted bioRxiv a license to display the preprint in perpetuity. It is made available under aCC-BY-ND 4.0 International license.

\begin{tabular}{|c|c|c|c|c|c|c|c|c|}
\hline geneSymbol & entrezID & ensg & gene_level_FDR & snplD & PIP & eSNP_cluster & $\mathrm{AF}$ & beta \\
\hline APRT & 353 & ENSG00000198931 & $2,20 \mathrm{E}-07$ & 16:88811768_C/A & 0,668248 & 1 & 0,017241379 & $-1,420888498$ \\
\hline APRT & 353 & ENSG00000198931 & $2,20 \mathrm{E}-07$ & 16:88082011_C/CG & 0,167905 & 1 & 0,973333333 & 1,162364612 \\
\hline APRT & 353 & ENSG00000198931 & $2,20 \mathrm{E}-07$ & 16:88079209_C/T & 0,162832 & 1 & 0,974358974 & 1,15139183 \\
\hline DAD1 & 1603 & ENSG00000129562 & $1,02 \mathrm{E}-11$ & 14:22589178_A/G & 0,952647 & 1 & 0,75862069 & $-0,565218707$ \\
\hline GPX4 & 2879 & ENSG00000167468 & 0,000934415 & 19:1104079_G/A & 0,964011 & 1 & 0,166666667 & 0,345933105 \\
\hline GTF2H1 & 2965 & ENSG00000110768 & 0,000932223 & 11:18321662_G/A & 0,234675 & 1 & 0,712643678 & 0,708757092 \\
\hline GTF2H1 & 2965 & ENSG00000110768 & 0,000932223 & 11:18322331_A/G & 0,192217 & 1 & 0,712643678 & 0,708757092 \\
\hline GTF2H1 & 2965 & ENSG00000110768 & 0,000932223 & 11:18322275_C/G & 0,192217 & 1 & 0,712643678 & 0,708757092 \\
\hline NME1 & 4830 & ENSG00000239672 & $3,34 \mathrm{E}-10$ & 17:51153130_A/T & 0,336428 & 1 & 0,408045977 & 0,524297468 \\
\hline NME1 & 4830 & ENSG00000239672 & $3,34 \mathrm{E}-10$ & 17:51154262_C/G & 0,265371 & 1 & 0,408045977 & 0,524297468 \\
\hline NME1 & 4830 & ENSG00000239672 & $3,34 \mathrm{E}-10$ & 17:51152947_T/C & 0,169729 & 1 & 0,408045977 & 0,524297468 \\
\hline RAD52 & 5893 & ENSG00000002016 & 0,001127433 & 12:792365_C/T & 0,505161 & 1 & 0,557471264 & $-0,876745977$ \\
\hline RAD52 & 5893 & ENSG00000002016 & 0,001127433 & 12:857042_G/A & 0,115504 & 1 & 0,568965517 & $-0,875319626$ \\
\hline RAD52 & 5893 & ENSG00000002016 & 0,001127433 & 12:813242_C/T & 0,0956224 & 1 & 0,563218391 & $-0,853034149$ \\
\hline TK2 & 7084 & ENSG00000166548 & 0,000157242 & 16:66550099_T/C & 0,463657 & 1 & 0,356321839 & 0,53268484 \\
\hline TK2 & 7084 & ENSG00000166548 & 0,000157242 & 16:66549744_A/G & 0,251954 & 1 & 0,350574713 & 0,530924135 \\
\hline TK2 & 7084 & ENSG00000166548 & 0,000157242 & 16:66549715_G/C & 0,251954 & 1 & 0,350574713 & 0,530924135 \\
\hline
\end{tabular}

Table 1: EQTL analysis of DNA repair genes in FSGS patients

Ensg: ensemble gene ID; FDR: false discovery rate, PIP: posterior inclusion probability, AF:

allele frequency, beta: expression difference to reference allele 


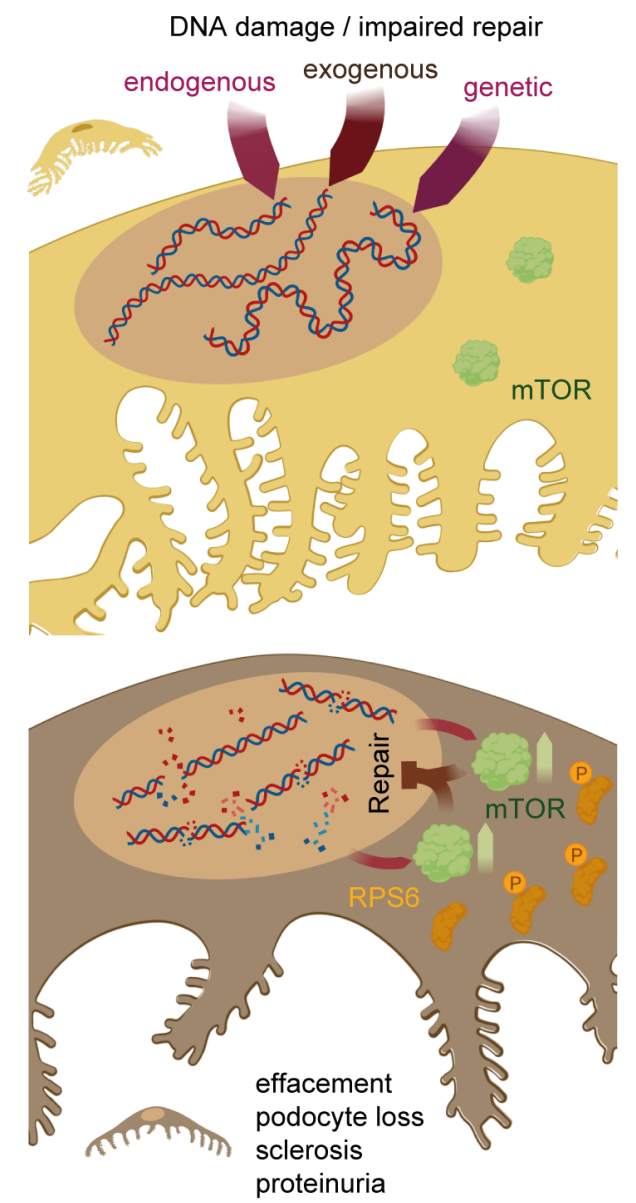

Visual Abstract

Schematic overview of main findings - Accumulation of genomic stress in podocytes occurs through endogenous or exogenous agents as well as genetic factors causing decreased DNA repair gene expression. Excessive DNA damage leads to the activation of $\mathrm{mTORC} 1$ triggering podocyte effacement, loss, glomerular scarring and proteinuric kidney disease.

\section{Supplementary Information:}

Table S1: Gene expression analysis of ERCB for Hallmark DNA Repair and Nucleotide Excision Repair Genes

Table S2: Clinical characteristics of FSGS patients

Table S3: EQTL analysis of DNA repair genes in FSGS patients 